\title{
Technology for the Remediation of Water Pollution: A Review on the Fabrication of Metal Organic Frameworks
}

\author{
Yongning Bian ${ }^{1,2}$, Nana Xiong ${ }^{1,2}$ and Guocheng Zhu ${ }^{1,2,3, *}$ \\ 1 Hunan Provincial Key Laboratory of Shale Gas Resource Utilization and Exploration, Xiangtan 411201, \\ China; byn1992@outlook.com (Y.B.); xiongnana2018@outlook.com (N.X.) \\ 2 College of Civil Engineering, Hunan University of Science and Technology, Xiangtan 411201, China \\ 3 School of Resource Environment and Safety Engineering, Hunan University of Science and Technology, \\ Xiangtan 411201, China \\ * Correspondence: zhuguoc@hnust.edu.cn or zgc945ahhn@163.com; Tel.: +86-731-5829-0269
}

Received: 29 June 2018; Accepted: 3 August 2018; Published: 8 August 2018

\begin{abstract}
The ineffective control of the release of pollutants into water has led to serious water pollution. Compared with conditions in the past, the polluting components in aquatic environments have become increasingly complex. Some emerging substances have led to a new threat to the safety of water. Therefore, developing cost-effective technologies for the remediation of water pollution is urgently needed. Adsorption has been considered the most effective operational unit in water treatment processes and thus adsorption materials have gained wide attention. Among them, metal organic frameworks (denoted as MOFs) have been rapidly developed in recent years due to their unique physicochemical performance. They are characterized by larger porosity and larger specific surface area, easier pore structure designing, and comfortable structural modification. In many fields such as adsorption, separation, storage, and transportation, MOFs show a better performance than conventional adsorption materials such as active carbon. Their performance is often dependent on their structural distribution. To optimize the use of MOFs, their fabrication should be given more attention, without being limited to conventional preparation methods. Alternative preparation methods are given in this review, such as diffusion, solvent thermal, microwave, and ion thermal synthesis. Furthermore, developing functionalized MOFs is an available option to improve the removal efficiencies of a specific contaminant through pre-synthetic modification and post-synthesis modification. Post-synthesis modification has become a recent research hotspot. The coupling of MOFs with other techniques would be another option to ameliorate the remediation of water pollution. On one hand, their intrinsic drawbacks may be reduced. On the other hand, their performance may be enhanced due to their interaction behaviors. Overall, such coupling technologies are able to enhance the performance of an individual material. Because the excellent performance of MOF materials has been widely recognized and their developments have received wide attention, especially in environmental fields, in the present work we provide a review of fabrication of MOFs so as to motivate readers to deepen their understanding of the use of MOFs.
\end{abstract}

Keywords: adsorption; metal organic frameworks; remediation; water pollution 


\section{Introduction}

Water pollution has become a serious problem, especially in those developing countries experiencing rapid economic development. The demands for clear water have increased, but the water treatment loadings have also increased. Thus, cost-effective water remediation technologies are currently in demand. Many methods for water treatment have been extensively used, such as adsorption [1], oxidation-reduction [2], membrane filtration [3,4], and coagulation-flocculation [5,6]. Among them, adsorption has long been used in water treatment processes, and further developments are expected to yield highly efficient adsorbents. Metal organic frameworks (MOFs) have been considered as the most effective porous materials for water purification. They have been defined as a type of network-structural porous materials, which can be generated through organic ligands and metal ions to form a complex metal-ligand by self-assembly. MOFs have a better effect on the removal of pollutants through various adsorption mechanisms such as open metal sites, electrostatic adsorption, $\pi-\pi$ bonding, hydrogen bonding, and acid-base adsorption [7]. They are considered to have advantages over traditional porous materials, indicating great potential for environmental applications [8].

Developing MOFs materials is not a simple process. Those factors, such as the coordination environment, coordination connection, central metal ions, and organic ligand, significantly affect the structure of MOFs during preparation [9]. Among them, the reaction conditions affecting MOFs' synthesis include temperature, the molar ratio of metal ion to organic ligand, solvents, reaction system $\mathrm{pH}$, ingredient concentration, and reaction time [10]. These factors will determine the structure and performance of the fabricated MOF. Therefore, finding a solution to prepare MOFs for better water purification is needed.

Fortunately, compared with conventional porous materials, MOFs are easier to design and control. Their preparations can be carried out under mild and controllable conditions, thus resulting in a larger surface area, higher porosity, higher thermal stability, and higher electro-chemical stability [11,12]. When removing a specific pollutant, the functionalization of MOFs is also easier to achieve through the adjustment of central metal ions, organic ligands, and external chemical groups or ingredients. In addition, coupling them with other technologies can exhibit a better performance. Although they have been used in many fields as drug carriers [13,14], sensors [15,16], catalysts [17], and hydrogen storage materials [18,19], research that has been devoted to MOFs used for the treatment of contaminants in water is scarce. How to design the MOFs to satisfy the demands for better water treatment is a big challenge, particular in understanding of the structures of MOFs. It is for this reason that we proposed this review.

Overall, MOFs have a wide development prospect in the remediation of water pollution due to their unique properties such as a large porous structure, low density, high adsorption capacity, and high specific surface area [20]. Besides their applications in storage, gas separation, and so on [21], they have the potential for application in liquid-solid separation. As such, the present work provides a review of the fabrication of MOFs, including their typical preparations, modifications and applications.

\section{Typical Preparation}

MOFs have various types and subtypes of products. Those MOFs with particular structures obtained in previous researches are presented in Table 1. 
Table 1. The shapes of metal organic frameworks found in previous research studies.

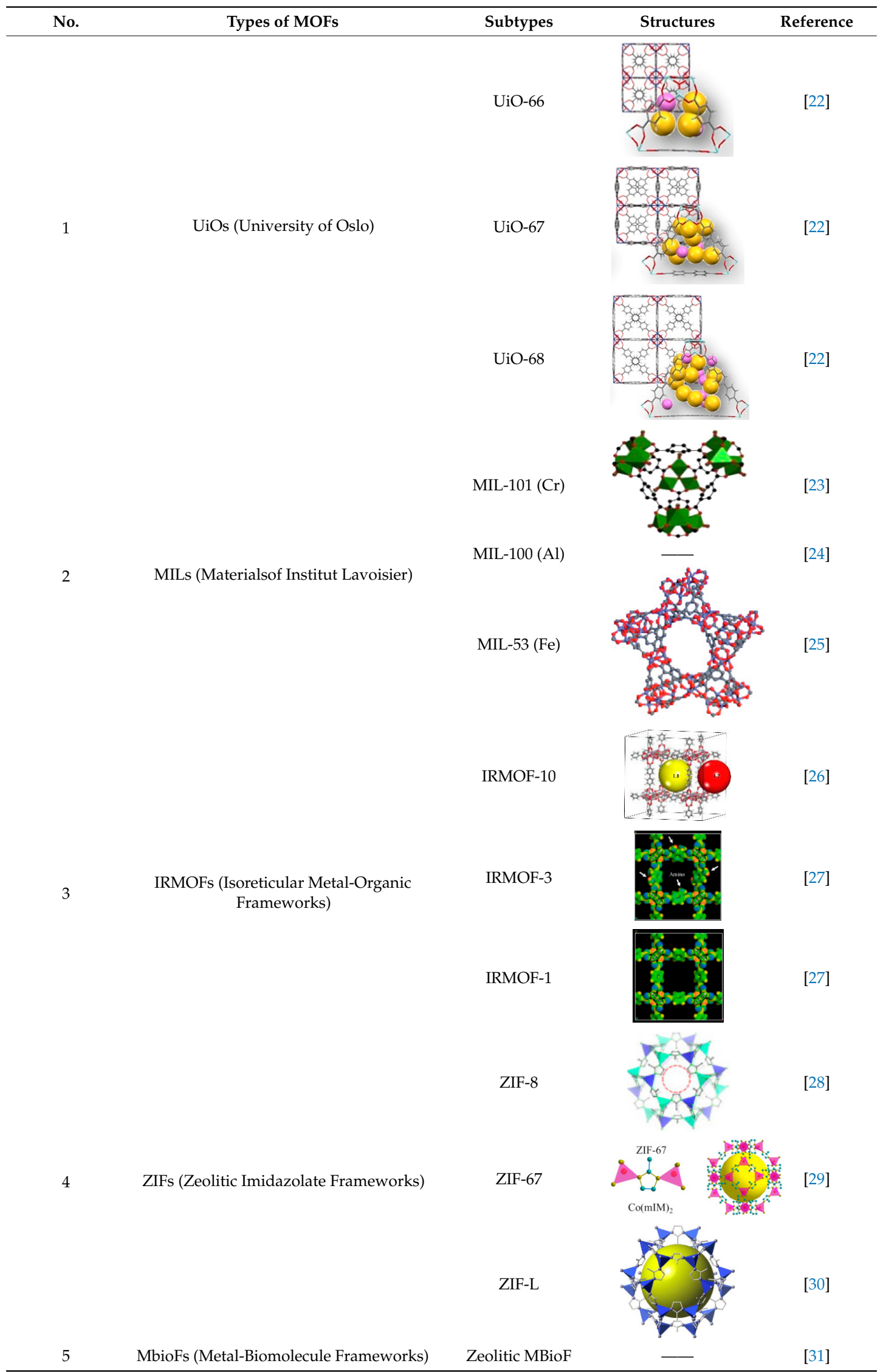


Table 1. Cont.

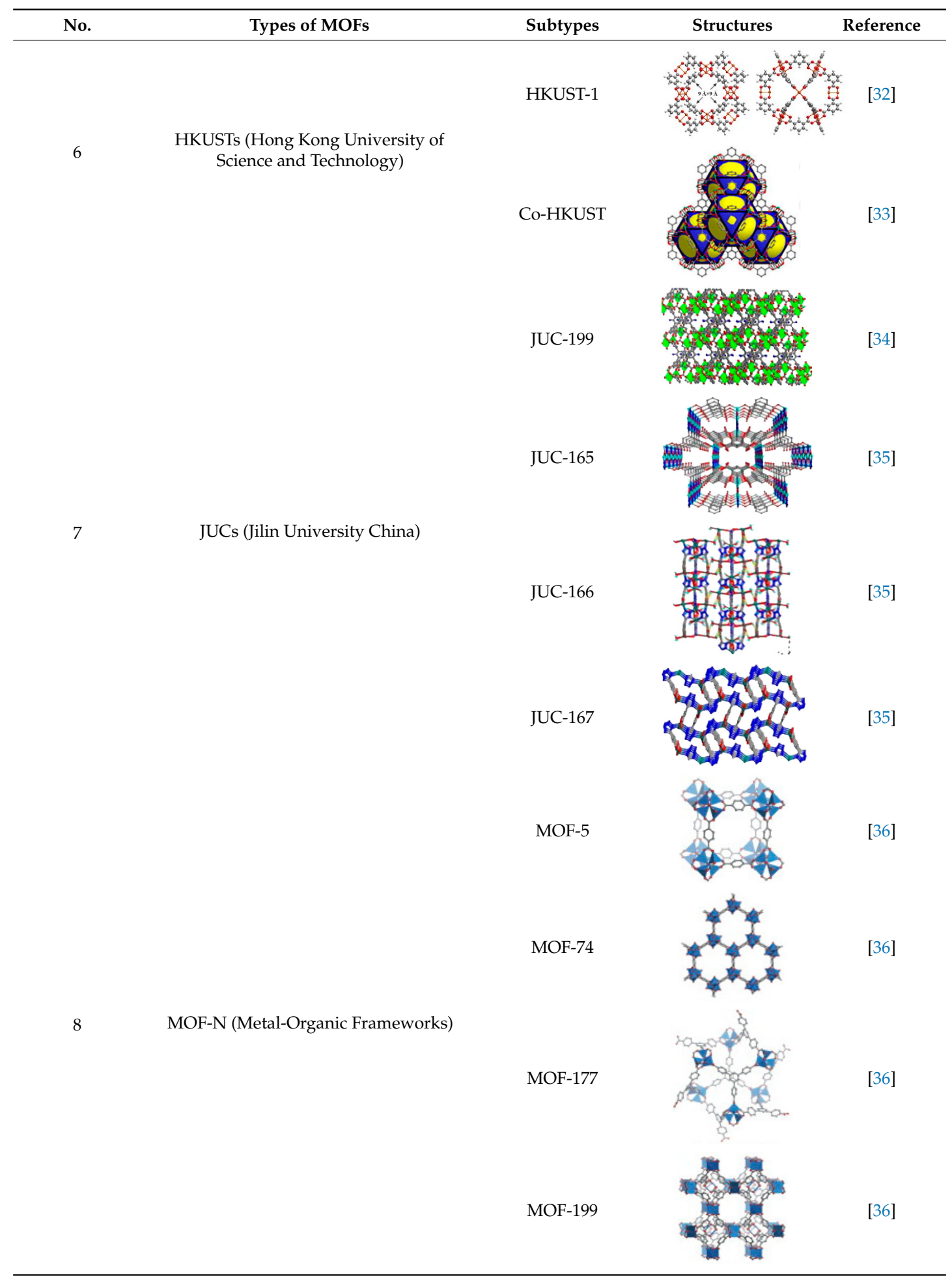

For the fabrication of the above MOFs, there are many applicable synthetic methods. The conventional solution method is conducted by mixing metal elements, organic ligands, and other raw materials at a certain proportion in a special solvent, with stirring for a certain time. The temperature is also fixed. A simple flow diagram showing the process of preparing MOFs is shown in Figure 1. Through filtration, the reaction product is collected for further solvent evaporation in order to obtain purified MOF crystals [37,38]. With this method, Ye et al. [39] synthesized a 
new type of ceramic base MOF: the crystal size and the symmetry of the product as well as the calcination temperature need to be strictly controlled in this preparation, and there are few inorganic non-metallic materials that can form optical ceramics. However, using the conventional solution method, the nanocrystals denoted as MAF-4 (sodalite-type zinc dimethyl imidazole known as ZIF-8) was able to produce a dense ceramic-like block. In addition, the optical ceramics had millimeter dimensions and were able to transmit up to $84 \%$ visible light.

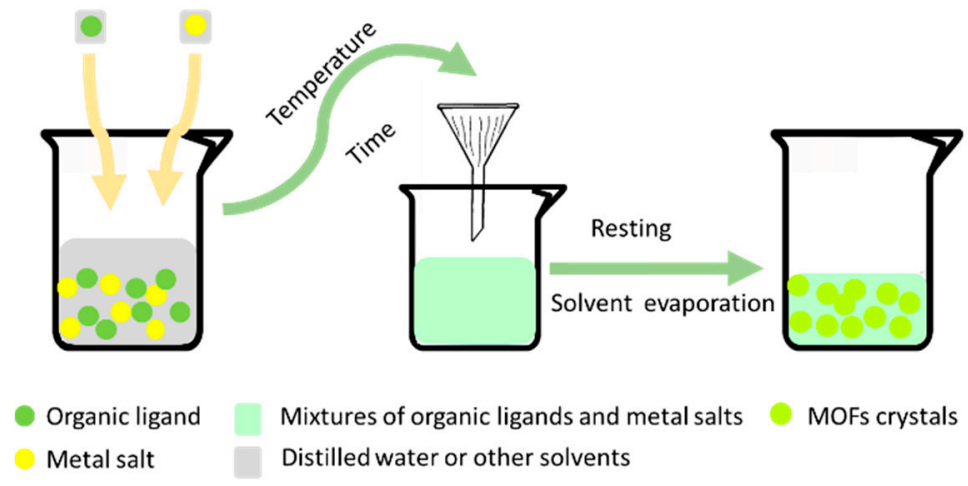

Figure 1. Schematic diagram for the synthesis of metal organic frameworks (MOFs) by the conventional solution method.

The diffusion method mainly consists of gel diffusion [40], liquid phase diffusion [41,42], and gas phase diffusion [43]. Gel diffusion is the method by which certain materials (such as organic ligand dispersed in a gel substance) and other materials (such as center metal ions solution) are mixed together for a period of time to produce MOF crystals through two branches of groups in gel [40]. Liquid phase diffusion is the method by which the center metal ions and organic ligands are dissolved in an incompatible solvent. They can form an MOF crystal product by being mixed together and reacting on their contact surface [42]. Gas phase diffusion is carried out using an organic volatile ligand solution as a solvent. The MOFs are generated during a sufficient reaction by mixing an organic ligands solution and a center metal ion solution [43]. The synthesis of MOFs by the diffusion method is often conducted under a mild reaction condition, but it is time-consuming [44]. Shearer et al. [45] used the diffusion method to synthesize UiO-66 by adding $\mathrm{ZrCl}_{4}, \mathrm{H}_{2} \mathrm{BDC}, \mathrm{H}_{2} \mathrm{O}$, and acetic acid to a conical flask containing $N, N^{\prime}$-dimethyllformamide. The mixtures were stirred until a transparent solution was obtained. In this study [45], the drawback was that it consumed too much reaction time-up to 14 days at $100{ }^{\circ} \mathrm{C}$. A simple schematic diagram for the synthesis of MOFs by gas phase diffusion is shown in Figure 2.

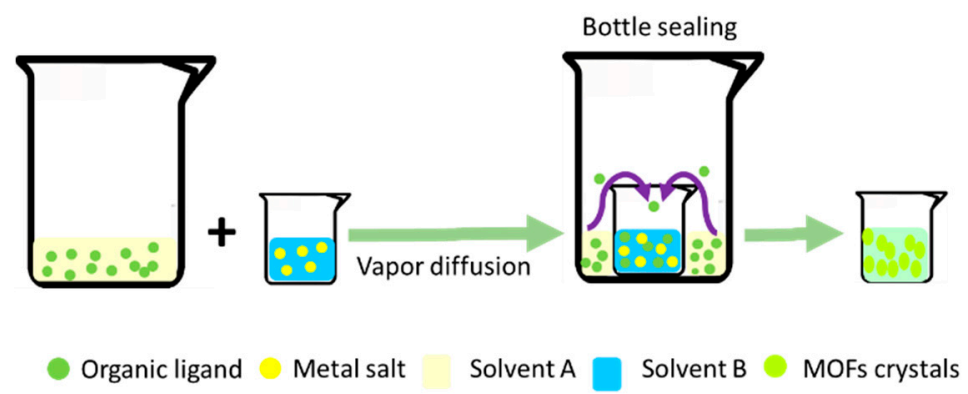

Figure 2. Schematic diagram for MOF synthesis by the gas phase diffusion method.

The hydrothermal method or solvent thermal method is carried out by mixing metal ions, organic ligands, regulators, reaction solvents, and other materials at a certain proportion in a polytetrafluoroethylene liner, which is then placed in a high temperature reactor to incite the reaction 
under a certain temperature. After the complete reaction, the reactor is cooled to room temperature and the product is washed repeatedly several times with deionized solutions (such as water) in order to remove impurities. Subsequently, the product is cleaned with anhydrous ethanol or other solutions at a setting temperature again. After vacuum-drying, the pure MOFs can be obtained [46-48]. The hydrothermal method uses water as a solvent [49]. A simple schematic diagram for MOF synthesis by the hydrothermal method or the solvent heating method is shown in Figure 3.

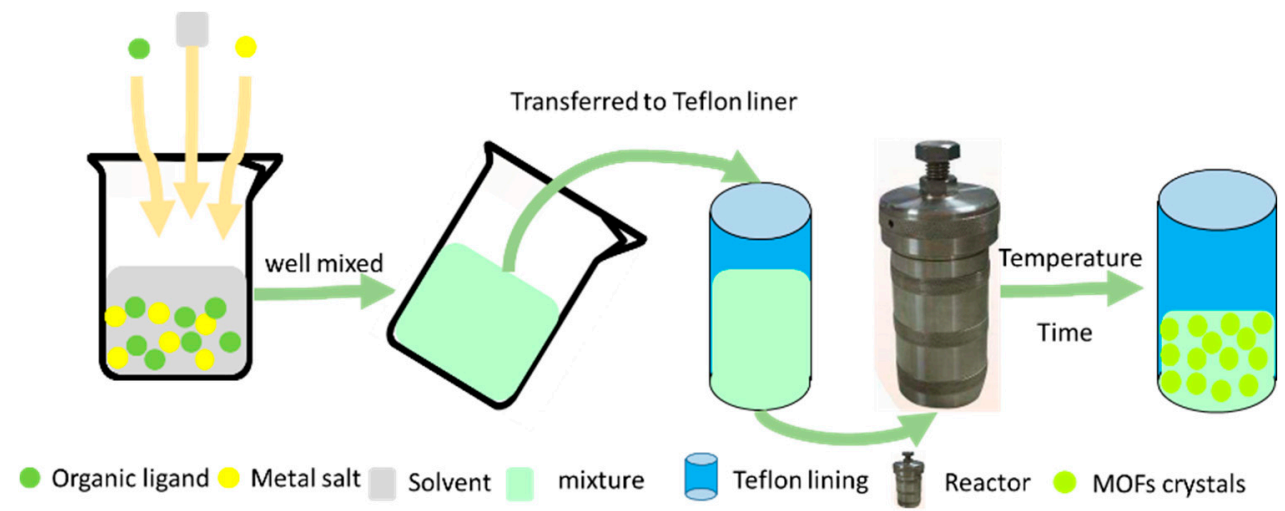

Figure 3. Schematic diagram for MOF synthesis by the hydrothermal method or the solvent heating method.

Wang et al. [50] synthesized Cu-based MOFs (denoted as $\mathrm{Cu}-\mathrm{MOFs}$ ) using the solvent thermal method. A brief process was developed as follows: $3.0 \mathrm{~g}$ of $\mathrm{Cu}\left(\mathrm{NO}_{3}\right)_{2} 3 \mathrm{H}_{2} \mathrm{O}$ in $30 \mathrm{~mL}$ of deionized water and $1.5 \mathrm{~g}$ of $\mathrm{H}_{3} \mathrm{BTC}$ in $30 \mathrm{~mL}$ of ethanol were mixed and sealed in a polytetrafluoroethylene-lined autoclave for a reaction time of $12 \mathrm{~h}$ at $120{ }^{\circ} \mathrm{C}$. When cooled to room temperature, the blue solid products were collected and washed alternately with ethanol and ultrapure water. Finally, the products were dried overnight at $60^{\circ} \mathrm{C}$ and fine blue $\mathrm{Cu}-\mathrm{MOF}$ powders were obtained. The solvent thermal method can obtain the products with a high crystallinity and a regular morphology structure, but it is time-consuming and its yields are relatively low [51].

The microwave method has the characteristics of rapid heating. With this method, there is no hysteresis effect and no temperature gradient. It can be used to synthesize those MOFs that have a high purity and crystallinity with less reaction time [52,53]. For instance, the crystal size $(<100 \mathrm{~nm})$ of UiO-66 that was synthesized by the microwave method was four times smaller than those prepared by the conventional heating method (about $400 \mathrm{~nm}$ ) [54]. The main reason for the good size obtained using the microwave method is that microwave heating can speed up nucleation, thus reducing the size of the crystals while increasing the number of nuclei in the crystals [54,55]. Yang et al. [56] used the microwave method to synthesize UiO-66, achieving products with a smaller aperture distribution. Compared with the traditional solvent heating method, the microwave method can greatly accelerate the reaction speed. As reported by Yang et al. [56], the synthetic time can be greatly reduced from $24 \mathrm{~h}$ to $30 \mathrm{~min}$. The above findings showed that the microwave method is a better option for the synthesis of MOFs. However, it is possible to cause partial cavity collapse or local carbonization of the carrier [57,58]. Therefore, ways to overcome these drawbacks during synthesis require careful consideration.

Ion thermal synthesis is used to design and synthesize MOFs in the hope of obtaining an ideal structure and properties [59]. In this method, an ionic liquid is used as reaction medium, structural template, or charge balance group; thus, it is considered a green synthesis method. The use of an ionic liquid as a solvent not only provides a pure ionic environment, but also acts as a structural template [60]. With this method, the physicochemical properties of MOFs can be controlled by changing the composition of the ionic liquid [60]. Further improving the yields and controllability of MOFs can be achieved by adjusting the structure, size, and polarity/hydrophilicity of the ionic liquid [61]. Ionic solutions are characterized by a liquid phase at or near room temperature. It is a 
kind of salt consisting of anions and cations [62,63]. Ionic liquids have many advantages, such as a lower melting point (generally less than $100{ }^{\circ} \mathrm{C}$ ), wider liquid range, and good thermal stability [62]. The ionic liquid can be used as both a solvent and template [64,65]. An ionic liquid such as [Bmim] [BF4] has been used as a solvent, structure-directing agent, fluoride source, and catalyst promoter, indicating a wide range of applications [66]. $\mathrm{Cd}_{3} \mathrm{~F}$-based MOFs were created during in situ ion thermal oxidation and hydrolysis, in which BF4-anions were filled in holes and/or channels [66].

The mechanochemical method, also known as the grinding method, can synthesize MOFs through mechanical agitation or collision between substances [67]. It is known for its low energy consumption and has become a recent research hotspot as a green synthesis method [68]. No heating process is required and no solvent or a small amount of solvent is consumed, and the reactant could be a metal oxide [69]. The reaction mainly occurs in the oxidation process, which produces only water as waste, consuming less energy and enabling green production [70]. In addition, this method's operation is simple and its production is highly efficient and easy [71]. Cheng et al. [72] synthesized a manganese-based MOF (denoted as Mn-MOFs) using the mechanochemical method. The reaction time to synthesize Mn-MOFs was about $24 \mathrm{~h}$ by liquid phase diffusion, but it took only $10 \mathrm{~min}$ to complete the reaction using the mechanochemical method, showing that the mechanochemical method was less time-consuming than the liquid phase diffusion method. Furthermore, using the mechanochemical method, the $\mathrm{Mn}_{2} \mathrm{O}_{3}$ had a better effect on the catalytic decomposition of ammonium perchlorate, which could lower the pyrolysis temperature by $158^{\circ} \mathrm{C}$, thus reducing the energy consumption.

\section{Modification of MOFs}

MOFs can be easily modified through chemical groups or other components. Specific modification is very conducive to the removal of targeted pollutants, and through the optimization of the skeleton surface it can be used for further improving the MOFs' performance. Because MOFs have a high porosity, solvent molecules can easily enter the interior channel and modify their inner and outer surfaces [73]. In addition, functional groups can also be easily introduced into MOFs [73]. Conventional modification is mainly carried out by pre-synthetic modification, in which the organic ligands are pre-functionalized so as to introduce a certain number of specific chemical groups into the ligands. At present, introducing multiple organic components or multiple groups into organic ligands to produce efficiently functionalized MOFs still requires the solvent thermal method. However, if under the solvent heating conditions those functional groups in ligands do not have good thermal stability, it will lead to group decomposition or ionic ligand [74]. Therefore, another modification called post-synthetic modification (PSM) [75] is used, which is conducted after the preparation of MOFs. Because the stability of most of MOFs in a water environment is fragile, post-synthetic modifications to water-sensitive MOFs are particularly needed [76]. Wen et al. [76] modified MOF crystals using a simple chemical coating with polydimethylsiloxane. The MOFs after modification could effectively remove crystalline violet from an aqueous solution and the maximum adsorption capacity was up to $129.87 \mathrm{mg} / \mathrm{g}$.

\subsection{Pre-Synthetic Modification}

The types of center metal ions and organic ligands in MOFs are important factors that affect their chemical structure and adsorption performance. Pre-synthetic modification often changes the structure of organic ligands by introducing target groups into MOFs, which has been widely used in extending the range of MOF applications [77]. During pre-synthetic modification, some groups (such as $-\mathrm{OH}$ [78] and - $\mathrm{COOH}$ [79]) are often studied, as they are grafted on organic ligands [80]. The commonly used chemical groups are listed in Table 2. All of the typical MOFs, such as MOF-5 [77], ZIFs [81], and MIL-53(Fe) [82], can be functionalized by pre-synthetic modification using the solvent heating method. In the preparation of MOFs, the ligand can be used alone. Besides, different functional ligands can also be mixed to produce MOFs [83]. For example, Bo et al. [84] mixed center metal ions solution and cellulose solution to obtain cellulose-modified MOFs (ZIF-8@CA) through a cross-linking agent 
using a conventional solvent method. A simple diagram showing the major steps for the pre-synthetic modification of MOFs is shown in Figure 4.

Table 2. Kinds of modifiers of different types of MOFs.

\begin{tabular}{cccc}
\hline MOFs & Modifiers & Kinds of Contaminants Absorbed & Reference \\
\hline BUC-17 & Graphene & Anionic dyes & {$[85]$} \\
MIL-88 (Fe) & Graphene oxide & Methylene blue; rhodamine B & {$[86]$} \\
UiO-66 & $-\mathrm{NH}_{2}$ & Doxycycline & {$[87]$} \\
MIL-101 $(\mathrm{Cr})$ & $-\mathrm{SO}_{3} \mathrm{Ag}$ & Iodide & {$[88]$} \\
ZJU-24 & $-\mathrm{COOH}$ & Methylene blue & {$[89]$} \\
UiO-66- & $-2 \mathrm{COOH}$ & $\mathrm{Cu}(\mathrm{II})$ & {$[90]$} \\
UiO-66 & $-\mathrm{OH}$ & Thorium ions & {$[78]$} \\
MIL-101 & $-\mathrm{SO}_{3} \mathrm{H}$ & Rosphin & {$[91]$} \\
MIL-101 $(\mathrm{Cr})$ & $-\mathrm{Br}$ & - & {$[92]$} \\
MIL-101 $(\mathrm{Cr})$ & $-\mathrm{F}$ & - & {$[92]$} \\
MIL-101 $(\mathrm{Cr})$ & $-\mathrm{CH}$ & - & {$[92]$} \\
MIL-101 $(\mathrm{Fe})$ & $-\mathrm{Cl}$ & - & {$[93]$} \\
\hline
\end{tabular}

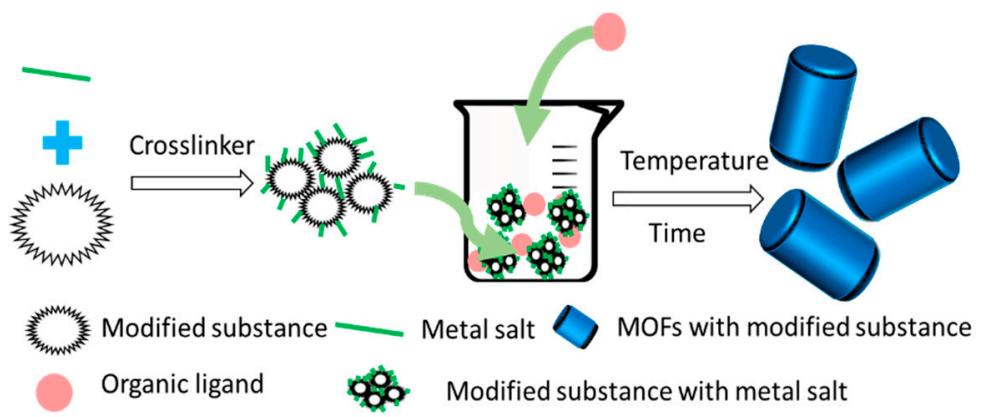

Figure 4. The route employed for the growth of MOFs with pre-synthetic modification.

\subsection{Post-Synthetic Modification}

Pre-synthetic modification is the process that modifies the composition of MOFs before the synthesis of MOFs, while post-synthetic modification is carried out after the synthesis of MOFs. The same results are obtained in that specific functional groups are grafted on ligands or metal vacancies in MOFs, thus realizing the functionalization of MOFs. It is a heterogeneous reaction process which forms those crystal materials with some chemical functional groups introduced into MOFs [94]. A diagram showing a simple post-synthetic modification process is shown in Figure 5. PSM is a useful method for preparing those MOFs with special functions. They can be obtained by adjusting the structure of MOFs through a coupling agent, metal joints, pore characteristics, and surface environment, thus improving their structural stability and performance [95]. However, the modification process can be time-consuming (usually 1-5 days). The production rate of MOFs is also largely dependent on the pore diameter of the raw materials under standard conditions.

Many improvements have been made on PSM, such as the coupling of PSM with liquid-phase impregnation (LP-PSM) [96] and the coupling of vapor phase with PSM (VP-PSM) [97]. LP-PSM is the method of immersing pre-synthesized MOFs in a solvent containing a modifier. With a long reaction time and repeated soakings, chemical groups can be grafted on MOFs. VP-PSM is one of pathways to overcome the drawbacks of PSM [97]. It can achieve a high yield within a short time and produce MOFs that exhibit a uniform distribution. It provides more flexibility in designing the applications of MOFs [97]. 


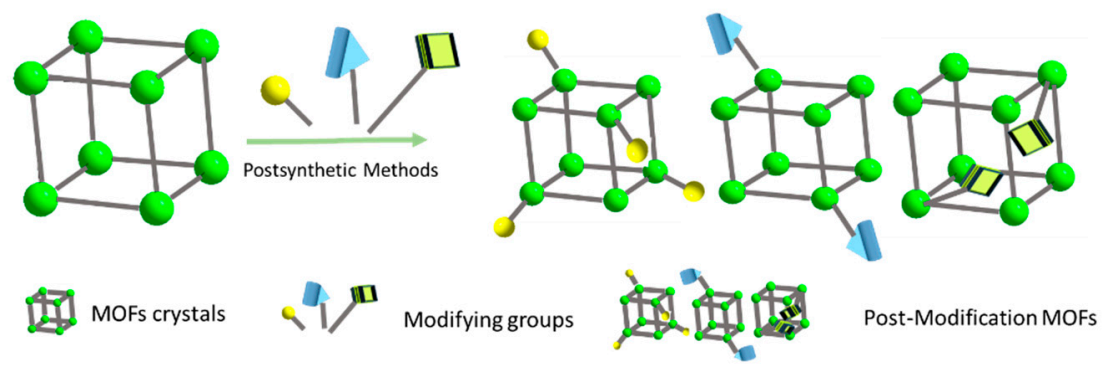

Figure 5. Schematic diagram of the post-synthetic modification of MOFs.

According to the breaking and formation of chemical bonds, PSM is often divided into covalent post-modification [98], coordinate covalent post-modification [99], and post-synthesis deportation [100]. These methods dominate PSM [75]. The groups introduced on MOFs in the covalent post-modification process contain $-\mathrm{NH}_{3},-\mathrm{OH}$, and $-\mathrm{NH}_{2}$ [101]. A simple diagram showing the major steps of covalent post-modification of MOFs is shown in Figure 6. In addition, Yoo et al. [102] synthesized an MOF denoted as IRMOF-3 and soaked it in a reaction solution for covalent modification. Cyanuric chloride was successfully grafted on the IRMOF-3-CC through the covalent bond formed between the amino group and the carbon group. The IRMOF-3-CC had a micro/medium pore structure and macroscopic morphology. An organic chain formed or broken after covalent post-modification is also shown in Figure 6.

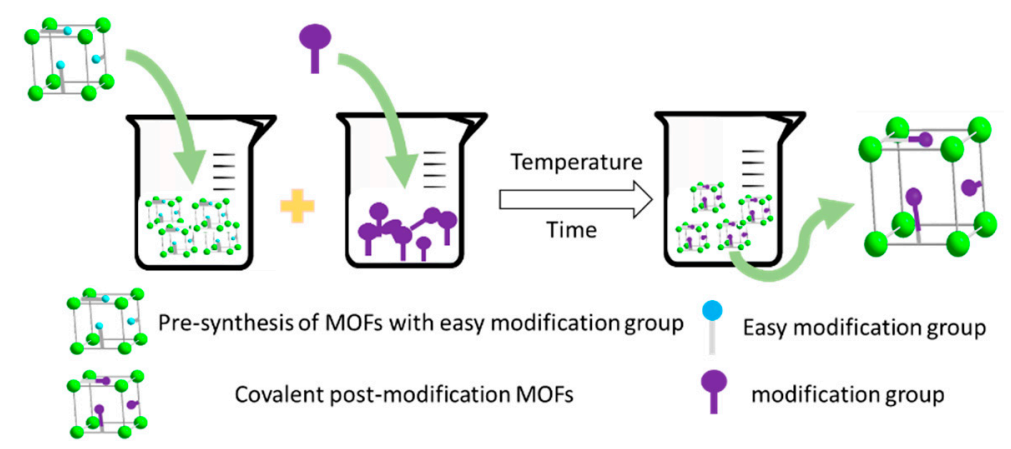

Figure 6. Schematic diagram for the covalent post-synthetic modification of MOFs.

Coordinate covalent post-modification usually modifies an unsaturated site of the metal ligand in MOFs. After coordination covalent modification, the coordination bonds of the metal-organic chain are formed. Some metal ions are possibly introduced to the MOF skeleton through an organic chain, thus forming coordination bonds [99]. A simple process of coordinate covalent post-modification is shown in Figure 7. 


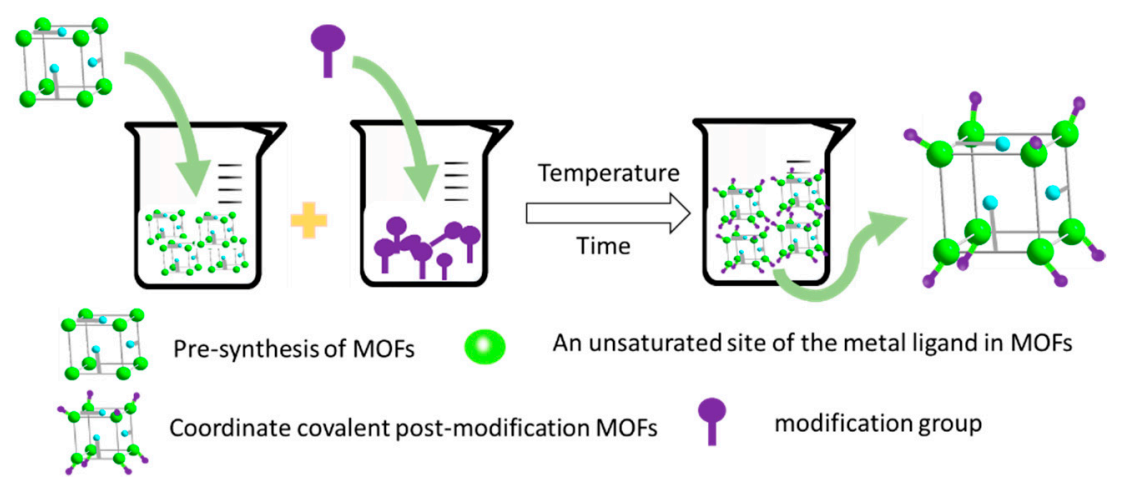

Figure 7. Schematic diagram for the coordinate covalent post-synthetic modification of MOFs.

In the post-synthesis deportation process, some groups and sites are easy to coordinate with metal ions, thus leading to the disappearance or loss of the catalytic activity of MOFs. Therefore, those active groups or catalytic active sites need to be protected before the synthesis of MOFs. After synthesis, the active groups or catalytic active sites will be removed $[100,103]$. A simple synthesis principle is shown in Figure 8.

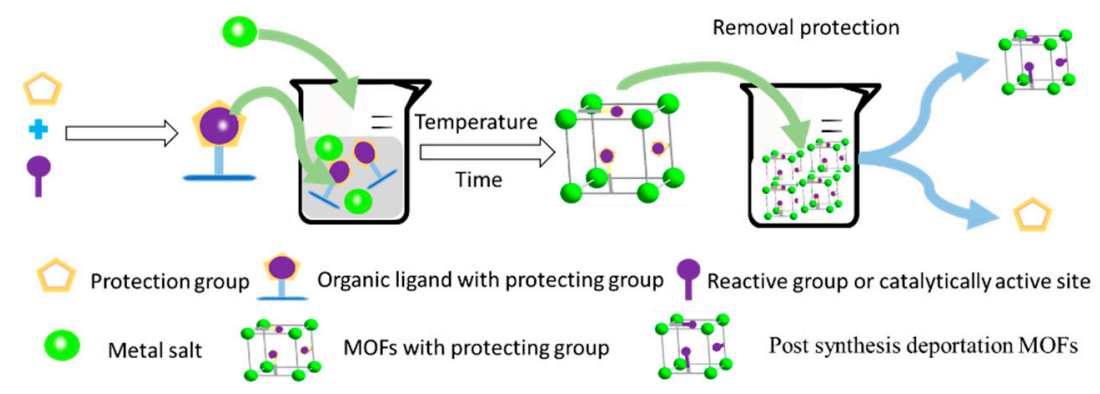

Figure 8. Schematic diagram for the post-synthesis deportation of MOFs.

Ko et al. [96] used PSM to prepare UMCM-1-NH $, 1-\mathrm{Me}, 1-\mathrm{Pr}, 1-\mathrm{Ph}$, and 1-PhCF3. They were soaked in acetic anhydride (Me), butyl anhydride (Pr), benzoic anhydride (Ph), and 4-(three fluorinated methyl) benzoic acid anhydride $\left(\mathrm{PhCF}_{3}\right)$ for 3 days, 6 days, 9 days, and 6 days, respectively. After soaking for 6 days, UMCM-1-NH $2,1-\mathrm{Me}, 1-\mathrm{Pr}, 1-\mathrm{Ph}$, and 1-PhCF 3 could be obtained. Their Brunauer-Emmet-Teller (BET) values were $4170 \mathrm{~m}^{2} / \mathrm{g}, 3550 \mathrm{~m}^{2} / \mathrm{g}, 2900 \mathrm{~m}^{2} / \mathrm{g}, 3680 \mathrm{~m}^{2} / \mathrm{g}$, and $3520 \mathrm{~m}^{2} / \mathrm{g}$, respectively. At $298 \mathrm{~K}$ and $253 \mathrm{~K}$, the carbon dioxide adsorption capacity for 1-Ph was more than $23 \%$ and 50\% higher than that for UMCM-1-NH2. Alqadami et al. [104] adopted PSM to obtain a mesoporous amide citric anhydride MOF (denoted as AMCA-MIL-53(Al)) by covalent bond modification among citric acid anhydride (CA), amino (- $\left.\mathrm{NH}_{2}\right)$, and $\mathrm{NH}_{2}-\mathrm{MIL}-53(\mathrm{~A} 1)$. At $318 \mathrm{~K}$, the maximum adsorption capacity of the divalent-led ion in a single layer was up to $390 \mathrm{mg} / \mathrm{g}$. Because of the motion instability of the coordination bonds of the metal-ligand in MOFs, those metal ions and organic ligands in some highly stable MOFs can be exchanged [95]. Based on the above findings, many new types of PSM have been developed, including post-synthetic metal exchange (PSME) [105,106], post-synthetic ligand exchange (PSLE) $[107,108]$, and post-synthetic elimination and installation (PSE\&I) [109]. Sun et al. [110] used PSME to prepare $\mathrm{NH}_{2}-\mathrm{UiO}-66(\mathrm{ZR} / \mathrm{Ti})$. The introduced Ti substituent promoted electron transfer, thus improving the performance of MOFs. Under visible light irradiation, they had a good photocatalytic effect on $\mathrm{CO}_{2}$ reduction and hydrogen evolution. Hong et al. [111] utilized PSLE to synthesize a series of porous metal-organic skeletons characterized by flexible carboxylic acid chains. A series of adipic acid were substituted for terephthalates in UiO-66 ligands. The selectivity of adsorption for $\mathrm{CO}_{2}$ and $\mathrm{CH}_{4}$ on $\mathrm{MOF}$ after ligand exchange was found to be significantly enhanced. Tu et al. [112] used post-synthetic elimination and installation (PSE\&I) 
to remove a quarter of the metal ions and half of the linking bonds in a cubic metal-organic skeleton, forming the ordered metal vacancies and linker vacancies in the cubic metal organic skeleton, and thus leading to an increase in the size of the pores. These vacancies would be filled with new metal ions and linking bonds. This method has the potential to enhance the functions of MOFs through the exchange of ingredients, without destroying their structural integrities.

\section{Effect of MOFs on the Remediation of Water Pollution}

MOFs have a large specific surface area and high porosity, which are beneficial to their applications in gas storage, separation, catalysis, and drug release, as well as in the reduction of heavy metals [113]. Hazardous metals have long been a serious threat to human health. Using common absorbents, the treatment efficiency would be not adequate to ensure safe water. The structure characteristics of pores are often the determining factor significantly affecting the performance of absorbents. It has been found that MOFs are feasible for the adsorption and diffusion of pollutants due to their good structure [114], especially with their larger specific surface area and porosity [115]. Those heavy metal ions that can be effectively removed by MOFs include cadmium, arsenic, chromium, lead, and mercury [116]. Through specific modifications, the adsorption performance for heavy metal ions of MOFs can be greatly enhanced. The heavy metal ions and their removal mechanisms by different MOFs are shown in Table 3. Saleem et al. [117] introduced thiourea, isothiocyanate, and isocyanate functional groups by PSM to UiO-66- $\mathrm{NH}_{2}$, which did not change their structure and thermal stability. The removal efficiency of heavy metal ions by MOFs could reach $99 \%$; the maximum adsorption capacities of $\mathrm{Cd}^{2+}, \mathrm{Cr}^{3+}, \mathrm{Pb}^{2+}$, and $\mathrm{Hg}^{2+}$ were $49 \mathrm{mg} / \mathrm{g}, 117 \mathrm{mg} / \mathrm{g}, 232 \mathrm{mg} / \mathrm{g}$, and $769 \mathrm{mg} / \mathrm{g}$, respectively. Tokalığlu et al. [118] prepared a zirconium-based MOF denoted as MOF-545 for the solid-phase extraction of $\mathrm{Pb}$ (II) from grains, beverages, and water samples. MOF-545 has a large adsorption capacity and pre-enrichment coefficient, of which the specific surface area was up to $2192 \mathrm{~m}^{2} / \mathrm{g}$, resulting in an adsorption capacity of $73 \mathrm{mg} / \mathrm{g}$. In addition, MOFs can be made into fluorescent probes for the selective detection of metal ions [119]. For example, El-Sewify et al. [120] prepared a fluorescent sensor using zirconium-based MOFs for the detection of heavy metal ions in water.

Besides their use in the removal of heavy metals, MOFs are also effective in the adsorption and photo-catalytic degradation of organic pollutants [121,122]. In fact, the adsorption effect of MOFs tested in a previous study was found to be better than that of commercial activated carbon [123]. Ramezanalizadeh et al. [124] treated methylene blue and 4-nitrophenol via photo-catalytic degradation with $\mathrm{MOFs} / \mathrm{CuWO}_{4}$, and found that the photo-catalytic efficiency of $\mathrm{MOFs} / \mathrm{CuWO}_{4}$ was significantly enhanced in the presence of MOFs. Zhou et al. [125] prepared zirconium-based MOFs, which had a strong adsorption for tibiotic tetracycline. Chen et al. [126] prepared a magnetic porous carbon-based adsorbent using a Fe (III)-based modified MOF-5, which had a good effect on the adsorption of five organic contaminants including 4-nitrophenol, Noroxin, bisphenol a, carbamazepine, and atrazine. Among them, it the adsorption of Noroxin via primary $\pi$-electron donor-acceptor interactions was the most effective. Azhar et al. [123] prepared HKUST-1 and UiO-66 by the solvothermal method and compared their removal performance to the removal of methylene blue $(\mathrm{Mb})$ in wastewater. Their preparations of MOFs can be employed over a wide $\mathrm{pH}$ range. The adsorption capacity with HKUST-1 was higher than that with UiO-66. 
Table 3. The effects of various types of MOFs on the removal of heavy metal ions.

\begin{tabular}{|c|c|c|c|c|c|c|c|c|}
\hline MOFs & $\begin{array}{l}\text { Preparation } \\
\text { Methods }\end{array}$ & Modification Methods & Modifiers & Contaminants & $\begin{array}{c}\text { Adsorption } \\
\text { Capacities (mg/g) }\end{array}$ & $\mathrm{pH}$ & Removal Mechanisms & Ref. \\
\hline $\mathrm{UiO}-66$ & $\begin{array}{l}\text { Solvothermal } \\
\text { method }\end{array}$ & Oven-promoted method & Melamine & $\mathrm{Pb}$ (II) & 205 & 6 & $\begin{array}{l}\text { The coordination interaction between the } \\
\text { amino groups }\left(-\mathrm{NH}_{2}\right) \text { and } \mathrm{Pb} \text { (II). }\end{array}$ & [127] \\
\hline MOF-74-Zn & $\begin{array}{l}\text { Solvothermal } \\
\text { method }\end{array}$ & - & - & $\mathrm{Hg}$ (II) & 63 & 6 & $\begin{array}{l}\text { Weak interactions between the MOF } \\
\text { skeleton (carboxylate and hydroxy group) } \\
\text { and } \mathrm{Hg}^{2+} \text { ions. }\end{array}$ & [128] \\
\hline ZIF-8@CA & $\begin{array}{l}\text { Solution } \\
\text { method }\end{array}$ & Pre-synthetic modification & $\begin{array}{l}\text { Flexible and porous } \\
\text { cellulose aerogels }\end{array}$ & $\mathrm{Cr}(\mathrm{IV})$ & 41.8 & - & $\begin{array}{l}N \text {-pyridine densely populated on the inner } \\
\text { surface of porous cellulose aerogels (CA) } \\
\text { with unique large specific surface areas and } \\
\text { a high density of adsorption sites. }\end{array}$ & [84] \\
\hline MIL-68 (W) & $\begin{array}{l}\text { Microwave } \\
\text { synthesis }\end{array}$ & $\begin{array}{l}\text { Liquid phase impregnation- } \\
\text { post-synthetic modification } \\
\text { (LP-PSM) }\end{array}$ & $\mathrm{Na}_{2} \mathrm{~S}$ & $\mathrm{Cd}(\mathrm{II})$ & 0.139 & - & $\begin{array}{l}\mathrm{Cd} \text { (II) was expected to bind to individual S } \\
\text { atoms rather than polymers, with dense } \\
\text { hydration spheres inhibiting sorption on } \\
\text { adjacent binding sites. }\end{array}$ & [129] \\
\hline $\mathrm{Cu}-\mathrm{MOFs}$ & $\begin{array}{l}\text { Solvothermal } \\
\text { method }\end{array}$ & Load modification & $\mathrm{Fe}_{3} \mathrm{O}_{4}$ & $\mathrm{~Pb}$ (II) & 219.00 & - & $\begin{array}{l}\text { The adsorption was chemical adsorption, } \\
\text { which is dominated by the coordination of } \\
\mathrm{Pb}^{2+} \text { with amino from } \mathrm{Cu}-\mathrm{MOF} \text {. }\end{array}$ & [130] \\
\hline HKUST-1 & $\begin{array}{l}\text { Solvothermal } \\
\text { method }\end{array}$ & LP-PSM & $\begin{array}{l}\text { Potassium nickel } \\
\text { hexacyanoferrate }\end{array}$ & Cs (I) & 153 & - & $\begin{array}{l}\text { A physical adsorption onto the crystal } \\
\text { lattice followed by strong electrostatic forces } \\
\text { could lead to chemical adsorption. }\end{array}$ & [131] \\
\hline $\mathrm{UiO}-66$ & $\begin{array}{l}\text { Solvothermal } \\
\text { method }\end{array}$ & LP-PSM & $\begin{array}{l}\text { Schiff base-derived } \\
\text { material }\end{array}$ & Co (II) & 256 & 8.4 & $\begin{array}{l}\text { The carboxyl oxygen and Schiff base } \\
\text { nitrogen in the ligand had a stronger } \\
\text { bonding ability towards Co (II) ions. }\end{array}$ & [132] \\
\hline
\end{tabular}




\section{Toward Better Development in the Remediation of Water Pollution}

To enhance environmental applications, MOFs can be coupled with many other materials such as high-molecular-weight organic polymers [133], nanoparticles [134], and inorganic carbon materials [135]. Three kinds of MOFs that can be better developed for water purification were selected as the examples in this review.

\subsection{The Coupling of MOFs with Membrane Systems}

To improve water treatment efficiency, MOFs materials can be coupled with other water treatment units such as membrane filtration [136]. Liu et al. [137] prepared a pure phase Zr-MOF polycrystalline film on alumina hollow fiber using an in situ solvothermal method. A simple flow diagram showing the major synthetic steps is depicted in Figure 9. Its performance was assessed by measuring gas permeation and ion exclusion. It showed good permeability and excellent polyvalent ion exclusion (e.g., $86.3 \%$ for $\mathrm{Ca}^{2+}, 98 \%$ for $\mathrm{Mg}^{2+}, 99.3 \%$ for $\mathrm{Al}^{3+}$ ). Also, Ingole et al. [138] improved the water vapor transport performance of mixed gas by combining MOFs and thin-film nanocomposite films, denoted as MOF@TFN4. The results showed that the maximum selectivity of the prepared MOF@TFN4 membrane was up to 542 and the maximum water vapor transmission rate was up to 2244 GPU. The coupling of the MOFs and membrane systems could be further developed under good operational conditions or coupling conditions. For example, Yin et al. [139] integrated amino-functionalized MOFs (denoted as $\mathrm{UiO}-66-\mathrm{NH}_{2}$ ) and ceramic membrane ultrafiltration to treat $\mathrm{Pb}$ (II) wastewater. Using transmembrane pressure, cross-velocity, reaction temperature, and average pore diameter at $0.15 \mathrm{MPa}, 4.0 \mathrm{~m} / \mathrm{s}, 35^{\circ} \mathrm{C}$ and $50 \mathrm{~nm}$, respectively, the ceramic membrane could completely retain the performance of the MOFs, and the removal rate of $\mathrm{Pb}$ (II) could reach $61.4 \%$. In the presence of MOFs, the properties of membranes were changed and some new functions were introduced, thus improving their performance. For example, Gholami et al. [140] synthesized a new hydrophilic TPU-5 polyethersulfone ultrafiltration membrane using the inversion method. Through the chemical modification of TPU-5 with the MOFs, denoted as TMU-5, the pore size and the porosity of the membrane were significantly increased, as were the hydrophilicity, pure water flux, and antifouling ability. As a result, the pure water flux could be increased to $182\left(\mathrm{~kg} / \mathrm{m}^{2} \mathrm{~h}\right)$ and $0.1 \mathrm{wt} \%$ recovery values of flux reached up to $98.74 \%$. The lowest resistance to irreversible fouling reached $1.25 \%$.

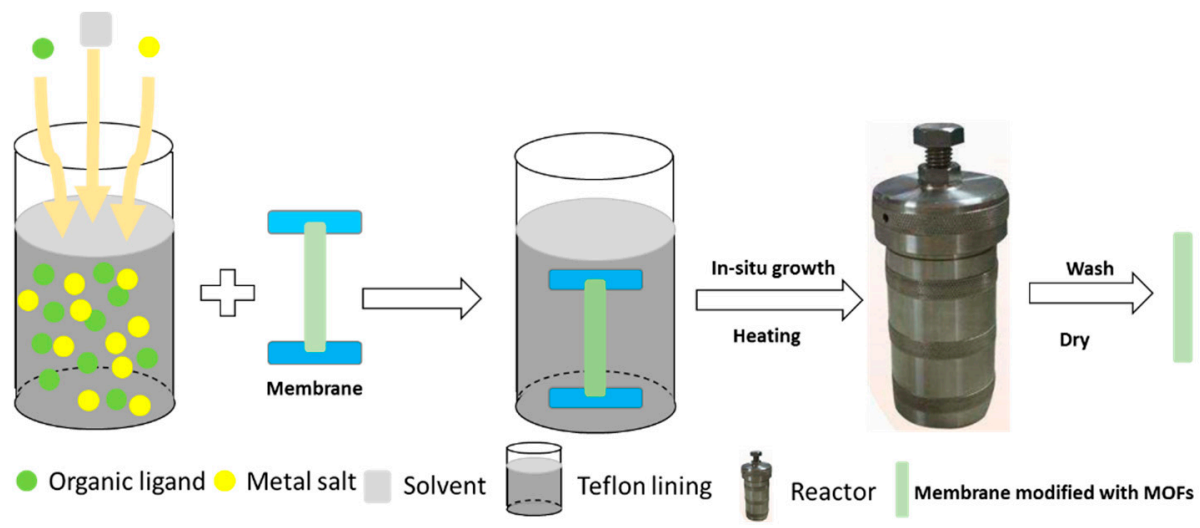

Figure 9. Schematic diagram for the solvothermal synthesis of an MOF-based membrane.

\subsection{The Coupling of MOFs with Magnetic Nanoparticles}

MOFs and magnetic nanoparticles are hybridized to form nanocomposites, which is conducive to the separation of those fine MOFs particles from water when placed in an external magnetic field. It has been reported that the coupling of superparamagnetic Nano- $\mathrm{Fe}_{3} \mathrm{O}_{4}$ and MOFs is able to increase the range of MOF applications [141]. Through the coupling, the magnetic separation of MOFs from water was easily realized [142,143]. Xu et al. [144] prepared a magnetic porous 
Ni@MOFs-74 (Ni) through a solvothermal reaction. The composite had better adsorption effects for the removal of rhodamine $b$ and ibuprofen-the adsorption capacities reached up to $177.8 \mathrm{mg} / \mathrm{g}$ and $4.1 \mathrm{mg} / \mathrm{g}$, respectively. Shi et al. [130] prepared a magnetic MOF (denoted as Cu-MOFs $/ \mathrm{Fe}_{3} \mathrm{O}_{4}$ ) using a solvothermal reaction. Adsorption experiments for $\mathrm{Pb}$ (II) and malachite green were carried out. The adsorption capacities of the two contaminants were $113.67 \mathrm{mg} / \mathrm{g}$ and $219.00 \mathrm{mg} / \mathrm{g}$, respectively. Huo et al. [145] prepared a core-shell based MOF (denoted as $\mathrm{Fe}_{3} \mathrm{O}_{4} @ Z$ ZIF-8), of which the surface area was up to $1133 \mathrm{~m}^{2} \cdot \mathrm{g}^{-1}$. Its maximum capacity of adsorption for As (III) reached up to $100 \mathrm{mg} / \mathrm{g}$, showing a higher adsorption effect than that of many traditional adsorbents. The possibly strong adsorption could be attributed to surface complexation interactions. Huang et al. [146] prepared a dual magnetic and amino group-modified zirconium-based MOF, which showed good removal efficiency for heavy metal ions and organic dyes. The highest capacities of adsorption for $\mathrm{Pb}^{2+}$ and methylene blue on MFC-N (UiO-66- $\mathrm{NH}_{2}$ ) were $102 \mathrm{mg} / \mathrm{g}$ and $128 \mathrm{mg} / \mathrm{g}$, respectively, while that for methyl orange on magnetic UiO-66 (MFC-O) was $219 \mathrm{mg} / \mathrm{g}$. The above findings showed that the coupling of MOFs with magnetic nanoparticles is a feasible option for the enhancement of MOFs' performance.

\subsection{The Coupling of MOFs with Graphene}

The coupling of MOFs with graphene oxide (GO) has potential to enhance the functions of MOFs. GO is defined as a soft two-dimensional carbon nanomaterial, consisting of a large number of oxygen-containing functional groups such as epoxy groups and carboxyl groups. It is characterized by a large specific surface area, high mechanical strength, and good electrical conductivity. GO could significantly increase the specific surface area of MOFs [147] and show a good adsorption effect. Liang et al. [148] found that with the increase of GO introduced in GO@MIL-101, both the integrity of the crystal composite and particle size were reduced, while with an appropriate dose the maximum capacity of adsorption for $\mathrm{Cr}$ (VI) could reach $125 \mathrm{mg} \cdot \mathrm{g}^{-1}$ with GO@MIL-101, which was $20 \%$ higher than that achieved with MIL-101. Wu et al. [149] synthesized a composite (MA/RG) using aluminum-based MOFs (MIL-68 (Al)) and reduced graphene oxide (RG) through a one-step solvothermal method. An adsorption experiment for liquid p-nitrophenol (PNP) was conducted, showing that introducing reduced graphene oxide (RG) could significantly alter the morphology of MIL-68 (Al), thus increasing the size of its surface area. The removal efficiencies of PNP by MA/ RG at the mass ratio of $15 \%$ of RG to MA were $64 \%$ and $123 \%$ higher than that achieved by MIL- 68 (Al) and RG alone, respectively. The major removal mechanisms were the hydrogen bonding and $\pi-\pi$ dispersion interactions.

\section{Summary}

With the increase of industry and agriculture, especially in developing countries, water pollution has become a serious environmental problem. Cost-effective technologies that address this issue are urgently needed. From this review, it can be seen that MOFs have great potential for the separation of pollutants from water. In this review, we detail various methods for the preparation of MOFs. In these methods, the selection and design of MOFs are closely correlated with their structural distributions, energy consumption, purity, yields, and the removal efficiencies of pollutants. How to obtain cost-effective MOFs should be the focus of fabrication research efforts. Fortunately, there are many types of MOFs having various structures that can be adjusted according to pre-determined settings. Although MOFs have poor water stability and even they are not easily separated from water due to their small size, it is feasible to couple them with other technologies. For example, coupling MOFs with magnetic materials can enhance their separation performance. Water purification by filtration through a membrane is the most promising technique for future development. MOFs can be subjected to changes in their physicochemical properties, thus improving their purification performance. Other materials such as nanoparticles, graphene, carbon nanotubes, and organic polymer are all potential materials to be coupled with MOFs. Overall, MOF-based hybrid materials are expected to play an important role in achieving further performance improvements in individual materials. Whatever the successes 
achieved so far, additional efforts on the fabrication of MOFs toward the achievement of better water purification are still needed.

Author Contributions: G.Z. led the academic direction and developed the manuscript; Y.B. and N.X. wrote this paper.

Funding: This research was funded by the Natural Science Foundation of Hunan Province of China grant number [2018J]2128], the China Postdoctoral Science Foundation (2017M622578), the National Natural Science Foundation of China (No. 51408215), and the Education Committee of Sichuan Province (17ZB0312).

Conflicts of Interest: The authors declare no conflict of interest.

\section{References}

1. Ma, J.; Shi, J.; Ding, H.; Zhu, G.; Fu, K.; Fu, X. Synthesis of cationic polyacrylamide by low-pressure UV initiation for turbidity water flocculation. Chem. Eng. J. 2017, 312, 20-29. [CrossRef]

2. Zhu, G.; Liu, J.; Yin, J.; Li, Z.; Ren, B.; Sun, Y.; Peng, W.; Liu, Y. Functionalized polyacrylamide by xanthate for $\mathrm{Cr}(\mathrm{VI})$ removal from aqueous solution. Chem. Eng. J. 2016, 288, 390-398. [CrossRef]

3. Yin, J.; Zhu, G.; Deng, B. Graphene oxide (GO) enhanced polyamide (PA) thin-film nanocomposite (TFN) membrane for water purification. Desalination 2016, 379, 93-101. [CrossRef]

4. Zhu, G.; Bian, Y.; Hursthouse, A.S.; Wan, P.; Szymanska, K.; Ma, J.; Wang, X.; Zhao, Z. Application of 3-D Fluorescence: Characterization of Natural Organic Matter in Natural Water and Water Purification Systems. J. Fluoresc. 2017, 27, 1-26. [CrossRef] [PubMed]

5. Zhu, G.; Wang, Q.; Yin, J.; Li, Z.; Zhang, P.; Ren, B.; Fan, G.; Wan, P. Toward a better understanding of coagulation for dissolved organic nitrogen using polymeric zinc-iron-phosphate coagulant. Water Res. 2016, 100, 201-210. [CrossRef] [PubMed]

6. Zhu, G.; Liu, J.; Bian, Y. Evaluation of cationic polyacrylamide-based hybrid coagulation for the removal of dissolved organic nitrogen. Environ. Sci. Pollut. Res. 2018, 25, 14447-14459. [CrossRef] [PubMed]

7. Kitagawa, S. Metal-organic frameworks (MOFs). Chem. Soc. Rev. 2014, 43, 5415-5418.

8. Kumar, P.; Bansal, V.; Kim, K.; Kwon, E.E. Metal-organic frameworks (MOFs) as futuristic options for wastewater treatment. J. Ind. Eng. Chem. 2018, 62, 130-145. [CrossRef]

9. Wang, L.P.; Wang, G.Y.; Wang, F.; Wang, P.H. Effect of Different Aromatic Carboxylic Acid Ligands on the Catalytic Activities of Metal-Organic Frameworks. Adv. Mater. Res. 2013, 634, 513-517. [CrossRef]

10. Deng, F.; Ding, W.; Peng, Z.; Li, L.; Wang, X.; Wan, X.; Cheng, L.; Li, M. The synthesis of ferrocene-based mixed-metal coordination polymer microspheres and their application in hydrogen storage. J. Alloy. Compd. 2015, 647, 1111-1120. [CrossRef]

11. He, Z.; Zhang, G.; Zhang, K.; Liao, C. Advances of Metal-Organic Frameworks in Adsorption and Separation Applications. Acta Chim. Sin. 2017, 75, 841-859.

12. Huo, J.; Cui, H.; Fu, M.; Yuan, B. The fabrication of magnetic metal-organic frameworks composites and their application in environment. Sci. Sin. Chim. 2017, 47, 830-843. [CrossRef]

13. Huxford, R.C.; Della Rocca, J.; Lin, W. Metal-organic frameworks as potential drug carriers. Curr. Opin. Chem. Biol. 2010, 14, 262-268. [CrossRef] [PubMed]

14. Horcajada, P.; Chalati, T.; Serre, C.; Gillet, B.; Sebrie, C.; Baati, T.; Eubank, J.F.; Heurtaux, D.; Clayette, P.; Kreuz, C. Porous metal-organic-framework nanoscale carriers as a potential platform for drug delivery and imaging. Nat. Mater. 2010, 9, 172-178. [CrossRef] [PubMed]

15. Kreno, L.E.; Leong, K.; Farha, O.K.; Allendorf, M.; Van Duyne, R.P.; Hupp, J.T. Metal-organic framework materials as chemical sensors. Chem. Rev. 2011, 112, 1105-1125. [CrossRef] [PubMed]

16. Hu, Z.; Deibert, B.J.; Li, J. Luminescent metal-organic frameworks for chemical sensing and explosive detection. Chem. Soc. Rev. 2014, 43, 5815-5840. [CrossRef] [PubMed]

17. Farrusseng, D.; Aguado, S.; Pinel, C. Metal-organic frameworks: Opportunities for catalysis. Angew. Chem. Int. Ed. 2009, 48, 7502-7513. [CrossRef] [PubMed]

18. Rosi, N.L.; Eckert, J.; Eddaoudi, M.; Vodak, D.T.; Kim, J.; O'Keeffe, M.; Yaghi, O.M. Hydrogen storage in microporous metal-organic frameworks. Science 2003, 300, 1127-1129. [CrossRef] [PubMed]

19. Suh, M.P.; Park, H.J.; Prasad, T.K.; Lim, D. Hydrogen storage in metal-organic frameworks. Chem. Rev. 2011, 112, 782-835. [CrossRef] [PubMed] 
20. Bhattacharya, S.; Bala, S.; Mondal, R. Design of chiral Co(II)-MOFs and their application in environmental remediation and waste water treatment. RSC Adv. 2016, 6, 25149-25158. [CrossRef]

21. Li, H.; Wang, K.; Sun, Y.; Lollar, C.T.; Li, J.; Zhou, H.C. Recent advances in gas storage and separation using metal-organic frameworks. Mater. Today 2018, 21, 108-121. [CrossRef]

22. Al-Jadir, T.M.; Siperstein, F.R. The influence of the pore size in Metal-Organic Frameworks in adsorption and separation of hydrogen sulphide: A molecular simulation study. Microporous Mesoporous Mater. 2018, 271, 160-168. [CrossRef]

23. Zhao, S.; Mei, J.; Xu, H.; Liu, W.; Qu, Z.; Cui, Y.; Yan, N. Research of mercury removal from sintering flue gas of iron and steel by the open metal site of Mil-101(Cr). J. Hazard. Mater. 2017, 351, 301-307. [CrossRef] [PubMed]

24. Sivasankar, K.; Devasenathipathy, R.; Wang, S.; Kohila, K.R.; Raja, D.S.; Lin, C. Synthesis of hierarchical mesoporous graphite oxide $/ \mathrm{Al}_{2} \mathrm{O}_{3}$ from MIL-100(Al) for the electrochemical determination of caffeic acid in red wine samples. J. Taiwan Inst. Chem. Eng. 2018, 84, 188-195. [CrossRef]

25. Liang, M.; Wu, Y.; Zhou, X.; Yan, J.; Xu, F.; Li, Z. Adsorption performance of MIL-100(Fe) for separation of olefin-paraffin mixtures. J. Taiwan Inst. Chem. Eng. 2016, 70, 74-78.

26. Liu, Z.; Zhang, K.; Wu, Y.; Xi, H. New functionalized IRMOF-10 with strong affinity for methanol: A simulation study. Appl. Surf. Sci. 2018, 440, 351-358. [CrossRef]

27. Isobe, T.; Arai, Y.; Yanagida, S.; Matsushita, S.; Nakajima, A. Solvothermal preparation and gas permeability of an IRMOF-3 membrane. Microporous Mesoporous Mater. 2017, 241, 218-225. [CrossRef]

28. Sun, J.; Semenchenko, L.; Lim, W.T.; Rivas, M.F.B.; Varela, V.-G.; Jeong, H.K. Facile synthesis of Cd-substituted zeolitic-imidazolate framework Cd-ZIF-8 and mixed-metal CdZn-ZIF-8. Microporous Mesoporous Mater. 2018, 264, 35-42. [CrossRef]

29. Wu, X.; Liu, W.; Wu, H.; Zong, X.; Yang, L.; Wu, Y.; Ren, Y.; Shi, C.; Wang, S.; Jiang, Z. Nanoporous ZIF-67 embedded polymers of intrinsic microporosity membranes with enhanced gas separation performance. J. Membr. Sci. 2017, 548, 309-318. [CrossRef]

30. Cho, H.Y.; Kim, J.; Kim, S.N.; Ahn, W.S. High yield 1-L scale synthesis of ZIF-8 via a sonochemical route. Microporous Mesoporous Mater. 2013, 169, 180-184. [CrossRef]

31. Wang, J.F.; Kang, Y.; Fang, W.H.; Zhang, L.; Zhang, J. Zeolitic metal-biomolecule frameworks based on supertetrahedral lithium clusters and hypoxanthine nucleobase. Inorg. Chem. Commun. 2016, 71, 82-85. [CrossRef]

32. Chen, Q.; Chen, Q.; Zhuang, C.; Tang, P.; Lin, N.; Wei, L. Controlled release of drug molecules in metal-organic framework material HKUST-1. Inorg. Chem. Commun. 2017, 79, 78-81. [CrossRef]

33. Marri, S.R.; Chauhan, N.; Tiwari, R.K.; Kumar, J.; Behera, J.N. Two novel 3D-MOFs (Ca-TATB and Co-HKUST): Synthesis, structure and characterization. Inorg. Chim. Acta 2018, 478, 8-14. [CrossRef]

34. Feng, X. Solvent-induced single crystal to single crystal transformation and "turn-on" fluorescence based on a dynamic 3D metal-organic framework. Inorg. Chem. Commun. 2017, 86, 249-252. [CrossRef]

35. Wang, X.; Pan, Y.; Li, Z.; Li, X.; Qiu, S.; Xue, M. Constructing three new metal-organic frameworks based on a mixed-donor ligand: Topological analysis and fluorescence properties. Polyhedron 2017, 122, 55-60. [CrossRef]

36. Tranchemontagne, D.; Hunt, J.; Yaghi, O. Room temperature synthesis of metal-organic frameworks: MOF-5, MOF-74, MOF-177, MOF-199, and IRMOF-0. Tetrahedron 2008, 39, 8553-8557. [CrossRef]

37. Liu, W.; Chen, H. 1D Energetic Metal-organic Frameworks: Synthesis and Properties. Mater. Rev. 2018, 32, 223-227.

38. Dai, J.; Xiao, X.; Duan, S.; Liu, J.; He, J.; Lei, J.; Wang, L. Synthesis of Novel Microporous Nanocomposites of ZIF-8 on Multiwalled Carbon Nanotubes for Adsorptive Removing Benzoic Acid from Water. Chem. Eng. J. 2018, 331, 64-74. [CrossRef]

39. Ye, J.W.; Zhou, X.; Wang, Y.; Huang, R.K.; Zhou, H.L.; Cheng, X.N.; Ma, Y.; Zhang, J.P. Room-temperature sintered metal-organic framework nanocrystals: A new type of optical ceramics. Sci. China Mater. 2018, 61, 424-428. [CrossRef]

40. Dhanya, V.S.; Sudarsanakumar, M.R.; Suma, S.; Ng, S.W.; Augustine, M.S.; Roy, S.M. Crystal structure, thermal decomposition, photoluminescence and magnetic studies of a new two dimensional metal-organic framework constructed from infinite chains of edge-sharing $\mathrm{CeO}_{6}\left(\mathrm{H}_{2} \mathrm{O}\right)_{2}\left(\mathrm{NO}_{3}\right)$ polyhedron with bullet shaped channels. Inorg. Chem. Commun. 2013, 35, 140-143. [CrossRef] 
41. Qiu, L.; Wan, F.; Zhu, B.; Sun, Y.; You, Y.; Chen, Y. Synthesis, Structure and Spectroscopy Study of a 1D Copper Coordination Polymer Based on a Carboxybenzyl Viologen Ligand and SCN-Anion. Spectrosc. Spectr. Anal. 2015, 35, 1340-1344.

42. Xie, D.; Xing, H.; Zhang, Z.; Yang, Q.; Yang, Y.; Ren, Q.; Bao, Z. Porous hydrogen-bonded organometallic frameworks for adsorption separation of acetylene and carbon dioxide. CIESC J. 2017, 68, 154-162.

43. Wu, J.; Zhao, B.; Huang, C.; Chen, D.; Zhu, B. Supramolecular Design of Coordination Complexes of Zn(II) and Vapor Adsorption for MeOH. Chem. J. Chin. Univ. 2016, 37, 1069-1074.

44. Wang, F.X.; Wang, C.C.; Wang, P.; Xing, B.C. Syntheses and Applications of UiO Series of MOFs. Chin. J. Inorg. Chem. 2017, 33, 713-737.

45. Shearer, G.C.; Forselv, S.; Chavan, S.; Bordiga, S.; Bjørgen, M.; Svelle, S. In Situ Infrared Spectroscopic and Gravimetric Characterisation of the Solvent Removal and Dehydroxylation of the Metal Organic Frameworks UiO-66 and UiO-67. Top. Catal. 2013, 56, 770-782. [CrossRef]

46. Guo, H.; Zheng, Z.; Zhang, Y.; Lin, H.; Xu, Q. Highly selective detection of $\mathrm{Pb}^{2+}$ by a nanoscale Ni-based metal-organic framework fabricated through one-pot hydrothermal reaction. Sens. Actuators B Chem. 2017, 248, 430-436. [CrossRef]

47. Liu, J.M.; Liu, T.; Wang, C.C.; Yin, X.H.; Xiong, Z.H. Introduction of amidoxime groups into metal-organic frameworks to synthesize MIL-53(Al)-AO for enhanced U(VI) sorption. J. Mol. Liq. 2017, 242, 531-536. [CrossRef]

48. Zhu, B.J.; Yu, X.Y.; Jia, Y.; Peng, F.M.; Sun, B.; Zhang, M.Y.; Luo, T.; Liu, J.H.; Huang, X.J. Iron and 1,3,5-Benzenetricarboxylic Metal-Organic Coordination Polymers Prepared by Solvothermal Method and Their Application in Efficient As(V) Removal from Aqueous Solutions. J. Phys. Chem. C 2012, 116, 8601-8607. [CrossRef]

49. Yang, F.; Huang, H.; Wang, X.; Li, F.; Gong, Y.; Zhong, C.; Li, J.R. Proton Conductivities in Functionalized UiO-66: Tuned Properties, Thermogravimetry Mass, and Molecular Simulation Analyses. Cryst. Growth Des. 2015, 15, 5827-5833. [CrossRef]

50. Wang, X.; Ma, X.; Huang, P.; Wang, J.; Du, T.; Du, X.; Lu, X. Magnetic Cu-MOFs embedded within graphene oxide nanocomposites for enhanced preconcentration of benzenoid-containing insecticides. Talanta 2018, 181, 112-117. [CrossRef] [PubMed]

51. Wang, C.C.; Li, J.R.; Lv, X.L.; Zhang, Y.Q.; Guo, G. Photocatalytic organic pollutants degradation in metal-organic frameworks. Energy Environ. Sci. 2014, 7, 2831-2867. [CrossRef]

52. Liang, W.; D'Alessandro, D.M. Microwave-assisted solvothermal synthesis of zirconium oxide based metal-organic frameworks. Chem. Commun. 2013, 49, 3706-3708. [CrossRef] [PubMed]

53. Ni, Z.; Masel, R.I. Rapid production of metal-organic frameworks via microwave-assisted solvothermal synthesis. J. Am. Chem. Soc. JACS 2006, 128, 12394-12395. [CrossRef] [PubMed]

54. Li, Y.; Liu, Y.; Gao, W.; Zhang, L.; Liu, W.; Lu, J.; Wang, Z.; Deng, Y.J. Microwave-assisted synthesis of UIO-66 and its adsorption performance towards dyes. Crystengcomm 2014, 16, 7037-7042. [CrossRef]

55. Vakili, R.; Xu, S.; Al-Janabi, N.; Gorgojo, P.; Holmes, S.M.; Fan, X. Microwave-assisted synthesis of zirconium-based metal organic frameworks (MOFs): Optimization and gas adsorption. Microporous Mesoporous Mater. 2018, 260, 45-53. [CrossRef]

56. Yang, L.; Cai, R.; Qi, W.; Sun, L.; Xu, F. Microwave synthesis and hydrogen storage performance of UiO-66. Chin. J. Power Sources 2016, 40, 1605-1608.

57. Wang, Y.; Wu, W.; Liu, X.; Liu, F.; Luo, Y. Comparison of Microwave Method, Ultrasonic Method and Traditional Methods for Preparing Cu/MIL-101. Contemp. Chem. Ind. 2014, 43, 2514-2516.

58. Li, C.; Huang, J.; Zhu, H.; Liu, L.; Feng, Y.; Hu, G.; Yu, X. Dual-emitting fluorescence of Eu/Zr-MOF for ratiometric sensing formaldehyde. Sens. Actuators B Chem. 2017, 253, 275-282. [CrossRef]

59. Dybtsev, D.N.; Chun, H.; Kim, K. Three-dimensional metal-organic framework with $(3,4)$-connected net, synthesized from an ionic liquid medium. Chem. Commun. 2004, 10, 1594-1595. [CrossRef] [PubMed]

60. Morris, R.E. Concepts in the ionothermal synthesis of zeolites and metal organic frameworks. Stud. Surf. Sci. Catal. 2008, 174, 33-42.

61. Kinik, P.; Uzun, A.; Keskin, S. Ionic Liquid/Metal Organic Framework Composites: From Synthesis to Applications. ChemSusChem 2017, 10, 2842-2863. [CrossRef] [PubMed]

62. Dr, P.W.; Prof, W.K. Ionic Liquids-New "Solutions" for Transition Metal Catalysis. Angew. Chem. Int. Ed. 2000, 39, 3772-3789. 
63. Turner, E.A.; Cory, C.P.; Singer, R.D. Use of ab Initio Calculations toward the Rational Design of Room Temperature Ionic Liquids. J. Phys. Chem. A 2003, 107, 2277-2288. [CrossRef]

64. Jin, K.; Huang, X.; Pan, L.; Li, J.; Appel, A.; Wherland, S. [Cu (I) (bpp)] BF4: The first extended coordination network prepared solvothermally in an ionic liquid solvent. Chem. Commun. 2002, 23, 2872-2873. [CrossRef]

65. Liu, H. Synthesis of Hierarchical Porous Metals Using Ionic-Liquid-Based Media as Solvent and Template. Acta Physico-Chim. Sin. 2018, 34, 325-326.

66. Xie, Z.L.; Feng, M.L.; Tan, B.; Huang, X.Y. The multifunctional roles of the ionic liquid [Bmim][BF4] in the creation of cadmium metal-organic frameworks. Crystengcomm 2012, 14, 4894-4901. [CrossRef]

67. Fuhua, W.; Zhao, L.; Liang, Y.; Yun, L.; Shuai, Z.; Ding, C. Research progress of preparation and application of metal-organic framework materials. Mod. Chem. Ind. 2017, 37, 33-37.

68. Singh, N.K.; Gupta, S.; Pecharsky, V.K.; Balema, V.P. Solvent-free mechanochemical synthesis and magnetic properties of rare-earth based metal-organic frameworks. J. Alloy. Compd. 2017, 696, 118-122. [CrossRef]

69. Klimakow, M.; Klobes, P.; Rademann, K.; Emmerling, F. Characterization of mechanochemically synthesized MOFs. Microporous Mesoporous Mater. 2012, 154, 113-118. [CrossRef]

70. Chen, Y.; Xiao, J.; Lv, D.; Huang, T.; Xu, F.; Sun, X.; Xi, H.; Xia, Q.; Li, Z. Highly efficient mechanochemical synthesis of an indium based metal-organic framework with excellent water stability. Chem. Eng. Sci. 2017, 158, 539-544. [CrossRef]

71. Ning, J.; Zhiyong, D.; Gongying, W.; Shaoying, L. Preparation of Metal-Organic Frameworks and Application for $\mathrm{CO}_{2}$ Adsorption and Separation. Prog. Chem. 2014, 26, 1645-1654.

72. Cheng, Z.; Peng, R.; Jin, B.; Wang, H.; Chu, S.; Zuo, J.; Lu, B. Low Temperature Solid Phase Synthesis of Manganese-based Metal-Organic Frameworks by High-speed Air Flow Method. Fine Chem. 2018, 35, 796-823.

73. He, X.; Yin, F.; Wang, H.; Chen, B.; Li, G. Metal-organic frameworks for highly efficient oxygen electrocatalysis. Chin. J. Catal. 2018, 39, 207-227. [CrossRef]

74. Bauer, C.A.; Timofeeva, T.V.; Settersten, T.B.; Patterson, B.D.; Liu, V.H.; Simmons, B.A.; Allendorf, M.D. Influence of connectivity and porosity on ligand-based luminescence in zinc metal-organic frameworks. J. Am. Chem. Soc. 2007, 129, 7136-7144. [CrossRef] [PubMed]

75. Cohen, S.M. Postsynthetic methods for the functionalization of metal-organic frameworks. Chem. Rev. 2012, 112, 970-1000. [CrossRef] [PubMed]

76. Wen, G.; Guo, Z. Facile modification of $\mathrm{NH}_{2}-\mathrm{MIL}-125$ (Ti) to enhance water stability for efficient adsorptive removal of crystal violet from aqueous solution. Colloids Surf. A 2018, 541, 58-67. [CrossRef]

77. Deng, H.; Doonan, C.J.; Furukawa, H.; Ferreira, R.B.; Towne, J.; Knobler, C.B.; Wang, B.; Yaghi, O.M. Multiple Functional Groups of Varying Ratios in Metal-Organic Frameworks. Science 2010, 327, 846-850. [CrossRef] [PubMed]

78. Moghaddam, Z.S.; Kaykhaii, M.; Khajeh, M.; Oveisi, A.R. Synthesis of UiO-66-OH zirconium metal-organic framework and its application for selective extraction and trace determination of thorium in water samples by spectrophotometry. Spectrochim. Acta Part A Mol. Biomol. Spectrosc. 2018, 194, 76-82. [CrossRef] [PubMed]

79. Rada, Z.H.; Abid, H.R.; Sun, H.; Wang, S. Bifunctionalized Metal Organic Frameworks, UiO-66-NO $-\mathrm{NO}_{2}-\mathrm{N}(\mathrm{N}=$ $\left.-\mathrm{NH}_{2},-(\mathrm{OH})_{2},-(\mathrm{COOH})_{2}\right)$, for Enhanced Adsorption and Selectivity of $\mathrm{CO}_{2}$ and $\mathrm{N}_{2}$. J. Chem. Eng. Data 2015, 60, 2152-2161. [CrossRef]

80. Fu, H.R.; Wang, F.; Zhang, J. The photoluminescence and gas sorption properties of three Cd(II) MOFs based on 1,3,5 benzenetribenzoate with $-\mathrm{NH}_{2}$ or $-\mathrm{OH}$ groups. Dalton Trans. 2014, 43, 4668-4673. [CrossRef] [PubMed]

81. Ban, Y.; Li, Y.; Liu, X.; Peng, Y.; Yang, W. Solvothermal synthesis of mixed-ligand metal-organic framework ZIF-78 with controllable size and morphology. Microporous Mesoporous Mater. 2013, 173, 29-36. [CrossRef]

82. Devic, T.; Horcajada, P.; Serre, C.; Salles, F.; Maurin, G.; Moulin, B.; Heurtaux, D.; Clet, G.; Vimont, A.; Grenã, J.M.; et al. Functionalization in flexible porous solids: Effects on the pore opening and the host-guest interactions. J. Am. Chem. Soc. 2010, 132, 1127-1136. [CrossRef] [PubMed]

83. Siu, P.W.; Brown, Z.J.; Farha, O.K.; Hupp, J.T.; Scheidt, K.A. A mixed dicarboxylate strut approach to enhancing catalytic activity of a de novo urea derivative of metal-organic framework UiO-67. Chem. Commun. 2013, 49, 10920-10922. [CrossRef] [PubMed] 
84. Bo, S.; Ren, W.; Lei, C.; Xie, Y.; Cai, Y.; Wang, S.; Gao, J.; Ni, Q.; Yao, J. Flexible and porous cellulose aerogels/zeolitic imidazolate framework (ZIF-8) hybrids for adsorption removal of Cr (IV) from water. J. Solid State Chem. 2018, 262, 135-141. [CrossRef]

85. Li, J.J.; Wang, C.C.; Fu, H.F.; Cui, J.R.; Xu, P.; Guo, J.; Li, J.R. High-performance adsorption and separation of anionic dyes in water using a chemically stable graphene-like metal-organic framework. Dalton Trans. 2017, 46, 10197-10201. [CrossRef] [PubMed]

86. Wu, Y.; Luo, H.; Wang, H. Synthesis of iron(III)-based metal-organic framework/graphene oxide composites with increased photocatalytic performance for dye degradation. RSC Adv. 2014, 4, 40435-40438. [CrossRef]

87. Lin, K.Y.; Liu, Y.T.; Chen, S.Y. Adsorption of fluoride to UiO-66- $\mathrm{NH}_{2}$ in water: Stability, kinetic, isotherm and thermodynamic studies. J. Colloid Interface Sci. 2016, 461, 79-87. [CrossRef] [PubMed]

88. Zhao, X.; Xiao, H.; Li, Z.; Huang, H.; Liu, D.; Zhong, C. Enhanced removal of iodide from water induced by a metal-incorporated porous metal-organic framework. Appl. Surf. Sci. 2015, 351, 760-764. [CrossRef]

89. Zhang, Q.; Yu, J.; Cai, J.; Song, R.; Cui, Y.; Yang, Y.; Chen, B.; Qian, G. A porous metal-organic framework with-COOH groups for highly efficient pollutant removal. Chem. Commun. 2014, 50, 14455-14458. [CrossRef] [PubMed]

90. Zhao, X.; Liu, D.; Huang, H.; Zhong, C. Highly selective and sensitive metal-organic framework fluorescent probe for $\mathrm{Cu}^{2+}$ through rational design of binding sites. Microporous Mesoporous Mater. 2016, 224, 149-154. [CrossRef]

91. Zhao, X.; Wei, Y.; Zhao, H.; Gao, Z.; Zhang, Y.; Zhi, L.; Wang, Y.; Huang, H. Functionalized metal-organic frameworks for effective removal of rocephin in aqueous solutions. J. Colloid Interface Sci. 2018, 514, $234-239$. [CrossRef] [PubMed]

92. Buragohain, A.; Couck, S.; Voort, P.V.D.; Denayer, J.F.M.; Biswas, S. Synthesis, characterization and sorption properties of functionalized Cr-MIL-101-X (X =-F, -Cl, - Br, $\left.-\mathrm{CH}_{3},-\mathrm{C}_{6} \mathrm{H}_{4},-\mathrm{F}_{2},-\left(\mathrm{CH}_{3}\right)_{2}\right)$ materials. J. Solid State Chem. 2016, 238, 195-202. [CrossRef]

93. Zhang, Y.; Wan, J.; Wang, Y.; Ma, Y. Synthesis of phosphotungstic acid-supported versatile metal-organic

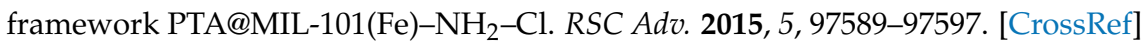

94. Koh, K.; Wongfoy, A.G.; Matzger, A.J. A porous coordination copolymer with over $5000 \mathrm{~m} 2 / \mathrm{g}$ BET surface area. J. Am. Chem. Soc. 2009, 131, 4184-4185. [CrossRef] [PubMed]

95. Yin, Z.; Wan, S.; Yang, J.; Kurmoo, M.; Zeng, M. Recent advances in post-synthetic modification of metal-organic frameworks: New types and tandem reactions. Coord. Chem. Rev. 2017. [CrossRef]

96. Ko, N.; Kim, J. Enhanced Carbon Dioxide Adsorption on Post-Synthetically Modified Metal-Organic Frameworks. Bull. Korean Chem. Soc. 2011, 32, 2705-2710. [CrossRef]

97. Servalli, M.; Ranocchiari, M.; Van, J.A. Bokhoven, Fast and high yield post-synthetic modification of metal-organic frameworks by vapor diffusion. Chem. Commun. 2012, 48, 1904-1906. [CrossRef] [PubMed]

98. Clements, J.E.; Price, J.R.; Neville, S.M.; Kepert, C.J. Perturbation of spin crossover behavior by covalent post-synthetic modification of a porous metal-organic framework. Angew. Chem. Int. Ed. 2014, 126, 10328-10332. [CrossRef]

99. Zheng, H.Y.; Lian, X.; Qin, S.J.; Yan, B. Lanthanide hybrids of covalently-coordination cooperative post-functionalized metal-organic frameworks for luminescence tuning and highly-selectively sensing of tetrahydrofuran. Dalton Trans. 2018, 47, 6210-6217. [CrossRef] [PubMed]

100. Kusaka, S.; Matsuda, R.; Kitagawa, S. Generation of thiyl radicals in a zinc(II) porous coordination polymer by light-induced post-synthetic deprotection. Chem. Commun. 2018, 54, 4782-4785. [CrossRef] [PubMed]

101. Song, Y.F.; Cronin, L. Postsynthetic Covalent Modification of Metal-organic Framework (MOF) Materials. Cheminform 2008, 47, 4635-4637. [CrossRef] [PubMed]

102. Yoo, Y.; Jeong, H.K. Generation of covalently functionalized hierarchical IRMOF-3 by post-synthetic modification. Chem. Eng. J. 2012, 181-182, 740-745. [CrossRef]

103. Zwoliński, K.M.; Nowak, P.; Chmielewski, M.J. Towards multifunctional MOFs-transforming a side reaction into a post-synthetic protection deprotection method. Chem. Commun. 2015, 51, 10030-10033. [CrossRef] [PubMed]

104. Alqadami, A.A.; Khan, M.A.; Siddiqui, M.R.; Alothman, Z.A. Development of citric anhydride anchored mesoporous MOF through post synthesis modification to sequester potentially toxic lead(II) from water. Microporous Mesoporous Mater. 2018, 261, 198-206. [CrossRef] 
105. Sumida, K.; Stück, D.; Mino, L.; Chai, J.D.; Bloch, E.D.; Zavorotynska, O.; Murray, L.J.; Dincă, M.; Chavan, S.; Bordiga, S. Impact of metal and anion substitutions on the hydrogen storage properties of M-BTT metal-organic frameworks. J. Am. Chem. Soc. 2013, 135, 1083-1091. [CrossRef] [PubMed]

106. Wright, A.M.; Rieth, A.J.; Yang, S.; Wang, E.; Dinca, M. Precise control of pore hydrophilicity enabled by post-synthetic cation exchange in metal-organic frameworks. Theranostics 2018, 8, 2424-2434. [CrossRef] [PubMed]

107. Hu, E.; Ning, J.; Zhao, D.; Xu, C.; Lin, Y.; Zhong, Y.; Zhang, Z.; Wang, Y.; Hu, Y. A Room-Temperature Postsynthetic Ligand Exchange Strategy to Construct Mesoporous Fe-Doped CoP Hollow Triangle Plate Arrays for Efficient Electrocatalytic Water Splitting. Small 2018, 14, e1704233. [CrossRef] [PubMed]

108. Park, H.; Kim, S.; Jung, B.; Park, M.H.; Kim, Y.; Kim, M. Defect Engineering into Metal-Organic Frameworks for the Rapid and Sequential Installation of Functionalities. Inorg. Chem. 2018, 57, 1040-1047. [CrossRef] [PubMed]

109. Yuan, S.; Chen, Y.P.; Qin, J.S.; Lu, W.; Zou, L.; Zhang, Q.; Wang, X.; Sun, X.; Zhou, H.C. Linker Installation: Engineering Pore Environment with Precisely Placed Functionalities in Zirconium MOFs. J. Am. Chem. Soc. 2016, 138, 8912-8919. [CrossRef] [PubMed]

110. Sun, D.; Liu, W.; Qiu, M.; Zhang, Y.; Li, Z. Introduction of a mediator for enhancing photocatalytic performance via post-synthetic metal exchange in metal-organic frameworks (MOFs). Chem. Commun. 2015, 51, 2056-2059. [CrossRef] [PubMed]

111. Hong, D.H.; Suh, M.P. Enhancing $\mathrm{CO}_{2}$ Separation Ability of a Metal-Organic Framework by Post-Synthetic Ligand Exchange with Flexible Aliphatic Carboxylates. Chem. Eur. J. 2014, 20, 426-434. [CrossRef] [PubMed]

112. Tu, B.; Pang, Q.; Wu, D.; Song, Y.; Weng, L.; Li, Q. Ordered vacancies and their chemistry in metal-organic frameworks. J. Am. Chem. Soc. 2015, 136, 14465-14471. [CrossRef] [PubMed]

113. Kuppler, R.J.; Timmons, D.J.; Fang, Q.; Li, J.; Makal, T.A.; Young, M.D.; Yuan, D.; Zhao, D.; Zhuang, W.; Zhou, H. Potential applications of metal-organic frameworks. Coord. Chem. Rev. 2009, 253, 3042-3066. [CrossRef]

114. Wen, J.; Fang, Y.; Zeng, G. Progress and prospect of adsorptive removal of heavy metal ions from aqueous solution using metal-organic frameworks: A review of studies from the last decade. Chemosphere 2018, 201, 627-643. [CrossRef] [PubMed]

115. Yaghi, O.M.; O'Keeffe, M.; Ockwig, N.W.; Chae, H.K.; Eddaoudi, M.; Kim, J. Reticular synthesis and the design of new materials. Nature 2003, 423, 705-714. [CrossRef] [PubMed]

116. Kobielska, P.A.; Howarth, A.J.; Farha, O.K.; Nayak, S. Metal-organic frameworks for heavy metal removal from water. Coord. Chem. Rev. 2018, 358, 92-107. [CrossRef]

117. Saleem, H.; Rafique, U.; Davies, R.P. Investigations on post-synthetically modified UiO-66- $\mathrm{NH}_{2}$ for the adsorptive removal of heavy metal ions from aqueous solution. Microporous Mesoporous Mater. 2016, 221, 238-244. [CrossRef]

118. Tokalığlu, Ş.; Yavuz, E.; Demir, S.; Patat, Ş. Zirconium-based highly porous metal-organic framework (MOF-545) as an efficient adsorbent for vortex assisted-solid phase extraction of lead from cereal, beverage and water samples. Food Chem. 2017, 237, 707-715. [CrossRef] [PubMed]

119. Pan, Y.; Wang, J.; Guo, X.; Liu, X.; Tang, X.; Zhang, H. A new three-dimensional zinc-based metal-organic framework as a fluorescent sensor for detection of cadmium ion and nitrobenzene. J. Colloid Interface Sci. 2018, 513, 418-426. [CrossRef] [PubMed]

120. El-Sewify, I.M.; Shenashen, M.A.; Shahat, A.; Yamaguchi, H.; Selim, M.M.; Khalil, M.M.; El-Safty, S.A. Dual colorimetric and fluorometric monitoring of $\mathrm{Bi}^{3+}$ ions in water using supermicroporous $\mathrm{Zr}-\mathrm{MOFs}$ chemosensors. J. Lumin. 2018, 198, 438-448. [CrossRef]

121. Zubair, H.; Jhung, S.H. Removal of hazardous organics from water using metal-organic frameworks (MOFs): Plausible mechanisms for selective adsorptions. J. Hazard. Mater. 2015, 283, 329-339.

122. Pi, Y.; Li, X.; Xia, Q.; Wu, J.; Li, Y.; Xiao, J.; Li, Z. Adsorptive and photocatalytic removal of Persistent Organic Pollutants (POPs) in water by metal-organic frameworks (MOFs). Chem. Eng. J. 2018, 337, 351-371. [CrossRef]

123. Azhar, M.R.; Abid, H.R.; Sun, H.; Periasamy, V.; Tadé, M.O.; Wang, S. One-pot synthesis of binary metal organic frameworks (HKUST-1 and UiO-66) for enhanced adsorptive removal of water contaminants. J. Colloid Interface Sci. 2017, 490, 685-694. [CrossRef] [PubMed] 
124. Ramezanalizadeh, H.; Manteghi, F. Synthesis of a novel MOF/CuWO heterostructure for efficient photocatalytic degradation and removal of water pollutants. J. Clean. Prod. 2018, 172, 2655-2666. [CrossRef]

125. Zhou, Y.; Yang, Q.; Zhang, D.; Gan, N.; Li, Q.; Jing, C. Detection and removal of antibiotic tetracycline in water with a highly stable luminescent MOF. Sens. Actuators B Chem. 2018, 262, 137-143. [CrossRef]

126. Chen, D.; Chen, C.; Shen, W.; Quan, H.; Chen, S.; Xie, S.; Luo, X.; Guo, L. MOF-derived magnetic porous carbon-based sorbent: Synthesis, characterization, and adsorption behavior of organic micropollutants. Adv. Powder Technol. 2017, 28, 1769-1779. [CrossRef]

127. Yin, N.; Wang, K.; Li, Z. Novel melamine modified metal-organic frameworks for remarkably high removal of heavy metal $\mathrm{Pb}(\mathrm{II})$. Desalination 2018, 430, 120-127. [CrossRef]

128. Xiong, Y.Y.; Li, J.Q.; Gong, L.L.; Feng, X.F.; Meng, L.N.; Zhang, L.; Meng, P.P.; Luo, M.B.; Luo, F. Using MOF-74 for $\mathrm{Hg}^{2+}$ removal from ultra-low concentration aqueous solution. J. Solid State Chem. 2017, 246, 16-22. [CrossRef]

129. Abney, C.W.; Gilhula, J.C.; Lu, K.; Lin, W. Metal-organic framework templated inorganic sorbents for rapid and efficient extraction of heavy metals. Adv. Mater. 2014, 26, 7993-7997. [CrossRef] [PubMed]

130. Shi, Z.; Xu, C.; Guan, H.; Li, L.; Fan, L.; Wang, Y.; Liu, L.; Meng, Q.; Zhang, R. Magnetic Metal Organic Frameworks (MOFs) Composite for Removal of Lead and Malachite Green in Wastewater. Colloids Surf. A Physicochem. Eng. Asp. 2018, 539, 382-390. [CrossRef]

131. Naeimi, S.; Faghihian, H. Performance of novel adsorbent prepared by magnetic metal-organic framework (MOF) modified by potassium nickel hexacyanoferrate for removal of $\mathrm{Cs}^{+}$from aqueous solution. Sep. Purif. Technol. 2017, 175, 255-265. [CrossRef]

132. Yuan, G.; Tian, Y.; Liu, J.; Tu, H.; Liao, J.; Yang, J.; Yang, Y.; Wang, D.; Liu, N. Schiff base anchored on metal-organic framework for Co (II) removal from aqueous solution. Chem. Eng. J. 2017, 326, 691-699. [CrossRef]

133. Bagheri, N.; Khataee, A.; Habibi, B.; Hassanzadeh, J. Mimetic Ag nanoparticle/Zn-based MOF nanocomposite (AgNPs@ZnMOF) capped with molecularly imprinted polymer for the selective detection of patulin. Talanta 2018, 179, 710-718. [CrossRef] [PubMed]

134. Falcaro, P.; Ricco, R.; Yazdi, A.; Imaz, I.; Furukawa, S.; Maspoch, D.; Ameloot, R.; Evans, J.D.; Doonan, C.J. Application of metal and metal oxide nanoparticles@MOFs. Coord. Chem. Rev. 2016, 307, 237-254. [CrossRef]

135. Zhang, K.; Wu, F.; Li, J.; Sun, M.; Xie, A.; Dong, W. Networks constructed by metal organic frameworks (MOFs) and multiwall carbon nanotubes (MCNTs) for excellent electromagnetic waves absorption. Mater. Chem. Phys. 2018, 208, 198-206. [CrossRef]

136. Kadhom, M.; Deng, B. Metal-organic frameworks (MOFs) in water filtration membranes for desalination and other applications. Appl. Mater. 2018, 11, 219-230. [CrossRef]

137. Liu, X.; Demir, N.K.; Wu, Z.; Li, K. Highly Water-Stable Zirconium Metal-Organic Framework UiO-66 Membranes Supported on Alumina Hollow Fibers for Desalination. J. Am. Chem. Soc. 2015, 137, 6999-7002. [CrossRef] [PubMed]

138. Ingole, P.G.; Sohail, M.; Abou-Elanwar, A.M.; Baig, M.I.; Jeon, J.D.; Choi, W.K.; Kim, H.; Lee, H.K. Water vapor separation from flue gas using MOF incorporated thin film nanocomposite hollow fiber membranes. Chem. Eng. J. 2018, 334, 2450-2458. [CrossRef]

139. Yin, N.; Wang, K.; Wang, L.; Li, Z. Amino-functionalized MOFs combining ceramic membrane ultrafiltration for $\mathrm{Pb}$ (II) removal. Chem. Eng. J. 2016, 306, 619-628. [CrossRef]

140. Gholami, F.; Zinadini, S.; Zinatizadeh, A.A.; Abbasi, A.R. TMU-5 Metal-Organic frameworks (MOFs) as a novel nanofiller for flux increment and fouling mitigation in PES ultrafiltration membrane. Sep. Purif. Technol. 2018, 194, 272-280. [CrossRef]

141. Zhan, H.; Bian, Y.; Yuan, Q.; Ren, B.; Hursthouse, A.; Zhu, G. Preparation and Potential Applications of Super Paramagnetic Nano-Fe $\mathrm{O}_{4}$. Processes 2018, 6, 33. [CrossRef]

142. Zhao, X.; Liu, S.; Zhi, T.; Niu, H.; Cai, Y.; Wei, M.; Wu, F.; Giesy, J.P. Synthesis of magnetic metal-organic framework (MOF) for efficient removal of organic dyes from water. Sci. Rep. 2015, 5, 1-10. [CrossRef] [PubMed]

143. Jabbari, V.; Veleta, J.M.; Zarei-Chaleshtori, M.; Gardea-Torresdey, J.; Villagrán, D. Green synthesis of magnetic MOF@GO and MOF@CNT hybrid nanocomposites with high adsorption capacity towards organic pollutants. Chem. Eng. J. 2016, 304, 774-783. [CrossRef] 
144. Xu, T.; Hou, X.; Liu, S.; Liu, B. One-step synthesis of magnetic and porous Ni@MOF-74 (Ni) composite. Microporous Mesoporous Mater. 2018, 259, 178-183. [CrossRef]

145. Huo, J.B.; Xu, L.; Yang, J.C.E.; Cui, H.J.; Yuan, B.; Fu, M.L. Magnetic responsive $\mathrm{Fe}_{3} \mathrm{O}_{4}$-ZIF-8 core-shell composites for efficient removal of As(III) from water. Colloids Surf. A: Physicochem. Eng. Asp. 2018, 539, 59-68. [CrossRef]

146. Huang, L.; He, M.; Chen, B.; Hu, B. Magnetic Zr-MOFs nanocomposites for rapid removal of heavy metal ions and dyes from water. Chemosphere 2018, 199, 435-444. [CrossRef] [PubMed]

147. Bandosz, T.J.; Petit, C. MOF/graphite oxide hybrid materials: Exploring the new concept of adsorbents and catalysts. Adsorption 2011, 17, 5-16. [CrossRef]

148. Liang, W.; Dan, T.; Anqi, L.; Bin, Z.; Shushuang, M.; Junjing, L.; Zhaohui, Z.; Xu, H. Preparation of graphene oxide@MIL-101 composite and its performance in $\mathrm{Cr}(\mathrm{VI})$ removal from aqueous solution. CIESC J. 2017, 68, 2105-2111.

149. Wu, Z.; Yuan, X.; Zhong, H.; Wang, H.; Zeng, G.; Chen, X.; Wang, H.; Zhang, L.; Shao, J. Enhanced adsorptive removal of p-nitrophenol from water by aluminum metal-organic framework/reduced graphene oxide composite. Sci. Rep. 2016, 6, 25638. [CrossRef] [PubMed]

(C) 2018 by the authors. Licensee MDPI, Basel, Switzerland. This article is an open access article distributed under the terms and conditions of the Creative Commons Attribution (CC BY) license (http:/ / creativecommons.org/licenses/by/4.0/). 